\title{
Evaluation of Technology Transferring
}

\section{The Experiences of the First Navy Domestic Technology Transfair}

\author{
FINAL REPORT
}

\author{
DISCLAIMER
}

This report was prepared as an account of work sponsored by an agency of the United States Government. Neither the United States Government nor any agency thereof, nor any of their Government. Neither the United States Government nor any agency thereof, hor any of the bility for the accuracy, completeness, or usefulness of any information, apparatus, product, or process disclosed, or represents that its use would not infringe privately owned rights. Reference herein to any specific commercial product, process, or service by trade name, trademark, manufacturer, or otherwise does not necessarily constitute or imply its endorsement, recommendation, or favoring by the United States Government or any agency thereof. The views and opinions of authors expressed herein do not necessarily state or reflect those of the United States Government or any agency thereof.

A report under Subcontract 9-LC2-1233F-1 by the American Defense Preparedness Association 
ATTACHMENTS

A. TRANSFAIR Participants/Exhibitors . . . . . 1

B. TRANSFAIR Presenters and Laboratories/

R\&D Centers Represented . . . . . . . 1-3

C. PANELS 1 through 12 ... ... . . . . . 1-5

D. A Scheiner-Principle Pocket optometer for

Self Evaluation and Biofeedback

Accommodation Training . . . . . . . 1

Electromagnetic Energy for the on-Site

Treatment of Severe Hypothermia . . . . .

Method and Apparatus for Treatment of

Hypothermia by Electromagnetic Energy . . 
RF Rewarming System . . . . . . . . . 4

Computer Control Unit Emulator CCU/E . . . 5

High-Strength, LOW-Al.loy Steels for Ship

Construction . . . . . . . . . . 6

Surface Effect Ship (SES) Technology . . . 7-8

Single-screw Air Compressors . . . . . 9

Single-screw Pump . . . . . . . . . 10

Variable Capacity Centrifugal Pump . . . . 11

Composite Materials for Ship Machinery

Applications . . . . . . . . . . 12

Design and Testing of a Balanced Air

Regulator for Deep Sea and Scuba Divers .

High-definitior, Video-Rate, Laser-

Addressed Liquid-Crystal Light-Valve

Projection Display . . . . . . . . . .

Real-Time, High-Resolution, 3-D Large-Screen

Display Using Laser-Activated Iiquid-

Crystal Light Valves . . . . . . . .

Real-Time, Ultra-High-Resolution Image

Projection Display Using Laser-Addressed

Liquid-Crystal Light Valve . . . . . 
Method and Apparatus for the Detection of Toxicants . . . . . . . . .

NRL Fluoropolymer Inventions, Materials, Uses, and Prospective Uses.......... 19 Holographic Optical Elements for Laser Diodes 20 Technological opportunities in Biomolecular Engineering . . . . . . . . . 21

Silver Oxide (AgO) Cathode ....... 22 Data Acquisition and Reduction Processor (DARP) for An/UYK-43(V) Performance Monitor Interface (PMI) . . . . . . Application of Global Positioning System Satellites to Determine Earth's Gravity and Platform orientation . . . . . . GPS-Aided Gravimetry at $30 \mathrm{~km}$ Altitude from a Balloon-Borne Platform . . . . . . 26 CMSTOOL Version 1.2 . . . . . . . 27 Magnetostrictive Sensors and Actuators . . 28 Method of Measuring Magnetic Effects Due to Eddy Currents . . . . . . . . . 
Nondestructive Inspection by Eddy Current

Methods of Carbon Fiber Reinforced

Composites and Metals . . . . . . . 30

Optimum Flow Noise Cancelling Hydrophone

Module . . . . . . . . . . . 32

Teletypewriter Loop Switching Matrix . . . 33

Magnetic Field Transducer Systems . . . . 34

Electronic Noise-Reducing System . . . . . 35

Symmetric Waveguide Junction Combiner . . . 36

Fire Extinguishing Material . . . . . 37

Improved Booster Explosive . . . . . 38-39 


\section{ABSTRACT}

From August 29 to 31, 1989 the Office of the Chief of Naval Research and the American Defense Preparedness Association conducted the first Navy Domestic Technology Transfair in Kansas City, Missouri. The objective of the Transfair was to expose the U.S. Navy's years of solid experience across a broad span of technology to organizations outside of the Navy. It was an opportunity for private industry to capitalize on the Navy developed technology and this opening for industry was the primary focus of the Transfair.

The event provided a unique forum to meet leading Navy scientific and engineering innovators face-to-face. Information was available concerning licensing of naval technology that was for sale to the private sector. Further, discussions covered opportunities for new cooperative research and development agreements with Navy laboratories and R\&D activities. These agreements were authorized under the Federal Technology Transfer Act of 1986. 
The Transfair program was conducted in such a manner as to allow each Navy inventor, either scientist or engineer, to present a system, piece of hardware, or licensable concept in a formal paper presentation. Then, the Navy inventors were available in two, two-hour "TRANSFAIR" periods in which individual discussions were conducted, one-on-one, with attendees pursuing specific venues of cooperative agreements as desired.

This report provides specifics concerning the technologies that were made available for transfer to the private sector during the Transfair. Whereas the Navy Transfair was the first combined Navy laboratory effort to promote technology transfer, it was not an exclusive condition whereby technologies had been, and are, available. The Transfair concept sought to add special emphasis to the opening that the 1988 Technology Transfer Act brought to the marketplace. At the same time, the experience was a step in the education of the possibilities for cooperation between the government and the private sector to share technology. Of additional significance is the economic enhancement for business expansion with the application of the technology to markets beyond defense. 


\section{EVALUATION OF TECHNOLOGY TRANSFERRING}

The Experiences of the First Navy Domestic Technology Transfair

The idea for technology transfer or, simply, sharing of information concerning developments by individuals or organizations is not new in itself and has been a function of companies and organizations for a long period of time. The first Navy Transfair, the Navy Domestic Technology Transfair, which was held in Kansas City, Missouri, from August 29th to the 31st of 1989, was unique, indeed, in its arrangement as well as the performance of the actual event itself. Before proceeding to understand the full results of this event and the value that was provided to the individual participants, whether they were presenting information or acquiring information or generally sharing with each other, it is appropriate to set the stage for how the Transfair was conducted.

More than a hundred individuals participated in this inaugural event. Some fifty presentations overall were delivered. In addition to a limited number of general speeches, of which there were only eleven, there were 39 technical presentations on Navy innovations dealing with 
Navy patents, or where patents had been applied for, and there were six general briefings related to domestic technology transfer. The special aspect of the event was the four "Transfair" sessions in which some twenty of the presenters were available in a one-on-one relationship for direct interaction with other attendees. (Attachment A) These individuals and their respective laboratories are set forth in Attachment B.

It was emphasized that this particular event was not a mere ceremonial function but it was a learning situation where the Navy summarized its key role in domestic technology transfer and, furthermore, the Navy outlined the reasons for holding the Transfair in relation to the total Navy technology transfer program.

The technical presentations were presented in twelve program modules of four presentations per module, Attachment c. Each of these was scheduled for a thirty minute time period. There were three two-hour sessions with two modules operating at one time and two two-hour sessions with three modules underway. Each module was moderated by a Navy representative, whether it was from the Office of Research and Technology Assessment or from one of 
the presenter commands in that module. Technologies were not grouped because of the diverse spread of technology and the license that had been offered for the presenters themselves. Technologies briefed are listed in Attachment $D$.

The four two-hour Transfairs provided the highlights of this event. Effort was made to have each scientist and inventor active at some point on each of the scheduled three days. In contrast to normal expectations, what this event offered was not just 40 examples of current naval technology suitable for transfer to the private sector but, also, an opportunity to get to know 40 innovative scientists and engineers and have them gain an appreciation of the private sector organizations represented. One can learn about specific technology by reading about it, but reading alone seldom leads to any transfers or cooperative research and development agreements (CDRAs). The Transfair one-on-one interface provided a special opportunity, in a planned program, targeted to technology transfer. Comments from those attending were revealing and informative. In particular, it was felt that licensing of 
patents is only one minor aspect of technology transfer. The more important point is the working relationship between scientists and those who are acquiring new technology for possible exportation into the commercial market. Technology transfers both ways. It transfers from the person who has invented the technology and acquired the patent, and then it transfers the other way, from those using that technology and putting it into practice for the benefit not only of the producer and seller but for those who are gaining the rewards which that technology now provides.

For industry to find the laboratories where there is a potential for these relationships, industry needs to be able to see what the broader scope is that is occurring at each of the labs. The Navy Transfair brought this together in one event at one time with a tremendous amount of leverage for those who participated and attended. It was, indeed, an unique arrangement.

There have been a number of meetings, often quite large, where a few people tell a lot of other people how to transfer technology. On the other hand, there have been a handful of smaller meetings where a few scientists and an 
equal number of people from industry share information on new products in a limited time period of discussion. The Navy Domestic Technology Transfair attempted to provide the best of both of these technical transfer worlds. The basis of the transfer plan was to conduct this particular meeting over a three-day period which was considered an appropriate amount of time for the number of technologies and scientists to explain their inventions and, at the same time, to justify the cost and the effort not only of those from the Navy laboratories who were presenting but also for those who were attending to learn new information.

There was a cosmetic value in choosing the center of the country to have this meeting, for it was made clear that the Navy was coming to the private sector, not vice versa, as a coastal site might have implied. On a very practical side, the Midwest lent a perception of lower costs which further supported the sincerity of the effort of dealing directly with the subject matter at the most reasonable investment.

Included with the one-on-one presentations were papers to appeal to scientists, engineers and managers from a sheer point of professionalism. There were three forms 
of programmed communication in the Transfair. There was the formal presentation with questions and answers in a technical atmosphere. Second, there was the informal one or two on one give and take of the Transfair. And finally, there was the instruction opportunity for private discussions during the many breaks, meal functions, and in the relationships that were developed amongst people who might have already been acquainted or who had been introduced at the Transfair.

It had been hoped from the outset that there might be perhaps a half-dozen cooperative research and development agreements that would evolve between attending organizations and the Navy. These could have involved specific technology or other spinoff generated by the discussions.

It was significant that the American Defense Preparedness Association played a key role in the support and organization of the Transfair. On the one hand, there was a captive membership audience which would provide sufficient attendees to bridge the gap until the Navy could reach out to small business, academic research and development, state and local governments, and those who are 
supposed to be anxious to use federal technology. Furthermore, the American Defense Preparedness Association, with its broad representation of industry for the United States industrial base, was in a unique position to expose the subject matter of the Transfair to a full spectrum of technology interests, not only from a defense point of view but also for the commercial market.

Arrangements also were made to permit, either upon request or by invitation to Navy or non-Navy-related activities, an opportunity to display tabletop exhibits manned during the transfer sessions in order to help expose other information in the sharing of technology to attendees. There were three primary exhibits. The Navy Domestic Technology Transfair fact sheet, the Mead Data Central on-Line Real-Time Database of 3,000 current Navy Patents, and considerable material from NASA's Cosmic Software Exchange Center at the University of Georgia. Also, some of the Navy research and development centers provided material concerning their activities. These were the Naval Surface Warfare Center, the David Taylor Research and Development Center, the Naval Underwater Systems Center, the Naval Ocean Systems Center, and the Naval 
Aerospace Medical Research Institute. Most of the attendees were from industry although it is interesting to note there was one Navy and one Air Force officer who attended the Transfair simply to view the technology. It was deduced that the term "technology transfer" is not clearly understood within the field itself and that many who attended the Transfair had little comprehension of domestic technology transfer in contrast to, for instance, international technology transfer.

In order to gather better information and to evaluate the success of the Transfair, evaluation forms were provided to each of the attendees. Forty-one percent of the attendees completed the forms. This is a very high percentage of return for meeting attendees in this setting. Nearly 58 percent of the non-Navy attendees were from industry, 11.5 percent were independent, and 7.7 percent, each, were from nonprofit and/or small business. Approximately 31 percent were from companies with more than 5,000 employees and a similar number from companies from 1,000 to 5,000 . The remaining 38 percent were divided equally between organizations of 100 to 999 , and organizations with 99 personnel or less. In addition to 
the scientists and engineers already noted, there were at least a half a dozen Navy ORTAs loffice of Research and Technology Assessment) from as many Navy R\&D activities.

It is interesting how this audience had been attracted. Thirty-six percent of those responding had learned of the Transfair from an American Defense Preparedness Association flyer which had been mailed. Eleven percent had received information by word of mouth. Eleven percent had received notification from their local ORTA. Of the remaining, 8.7 percent learned from direct contact with the director of the program from the office of Naval Research; 8.7 percent learned from the Navy Domestic Technology Transfer Fact Sheet; 8.7 percent learned from the Commerce Business Daily; 6.5 percent got their information from the Industrial Supervisor; and 6.5 percent received information from their local patent counsel. Two percent stated that they had learned of the Transfair from an Aviation Week advertisement.

When one considers the number of attendees, it could be observed that there were two errors in seeking attendance for the conference. First, the general announcement was made too late. Furthermore, submission to 
the Commerce Business Daily for exposure was made too late. This announcement occurred on August the 1st, 1989. In retrospect, it is considered that this announcement should have been made a month earlier, if not even sooner. In analyzing this particular aspect, insufficient attention had been given to the fact that the Transfair was a new event and needed more seasoning time for prospective attendees. Suitable lists of potentially interested individuals beyond the normal ADPA membership list were not acquired. However, the Transfair did open new means to such lists, both national and regional. It is considered that in a subsequent event both of these problems will be surmounted with ease.

To address, a moment, the Navy Domestic Technology Fact Sheet, among the total who responded to the evaluation, 42 percent were subscribers before the Transfair. It is estimated that after the Transfair, 91 percent of those attending became subscribers. By audience, the pre-Transfair subscribers were 38 percent of the non-Navy attendees and 47 percent of the Navy attendees. This would indicate that the exhibit of the Navy Domestic Technology Fact Sheet is well worth retaining 
in any future events.

A more detailed evaluation by attendees and speakers of the Transfair reveals that 43.5 percent of the total attendees submitted evaluations, 47.5 percent of the Navy speakers returned their questionnaires, 41 percent of the non-Navy attendees returned the questionnaire.

The popularity of the unique Transfair sessions was very high. Attendance at the Transfair sessions was 98 percent overall. Acceptance of the Transfair sessions was at the 91 percent level. Ninety-five percent of the Navy participants and 88 percent of all non-Navy attendees and 92 percent of all those who actually attended the Transfair session said that they supported the arrangement. Comparison of the face-to-face technology encounters versus merely reading about the same technology led to a 93.3 percent preference for face-to-face exchanges. It appeared that the ranking of the program elements was such that the Transfair sessions received the highest marks, followed by the informal networking during the non-conference periods of food functions or social events. Third in importance were the individual presentations, fourth was an amalgamation of the entire program itself, and the last 
item of importance were the written handouts available to all attendees.

The evaluation of exhibits was commented on only from about half of the respondents. There were no significant differences in exhibit evaluation from either the Navy speakers or the non-Navy attendees. There was only limited variation in opinions of the different exhibits. Two points seem worthy of note. The Mead Data Exhibit, with its working computer and the database of 3,000 Navy patents, was the overwhelming favorite of all. The Navy Domestic Technology Transfer Fact Sheet booth stood at the bottom among all exhibits evaluated. This was attributed to the fact that many of the attendees were already subscribers and were familiar with the Fact sheet. Since almost all reporting participants who were not already Fact Sheet subscribers did sign up, the low evaluation is interesting. It might very well be that the physical presentation of the booth was less than exciting. The view of the working session atmosphere of the Transfair reached a high approval level, reaching almost 90 percent, specifically, it was 88.6 percent. Consideration was asked concerning the future of Transfairs which might 
highlight four or five different technologies at a time. This was considered by 77.5 percent of those responding to be a good idea. The prospects of cooperative research and development agreements between the attendees' organizations and the Navy in the near future received an 80 percent expectation that this would happen. What was significant, that of those responding to a follow-on question, 100 percent indicated that after the Transfair they knew how to proceed to arrange a cooperative research and development agreement.

Approval of a structure of the meeting format was nearly universal among all those providing evaluations in both categories. Comments ranged around the technological diversity as being fascinating. A number of detailed and valuable suggestions were made. Five received sufficient support to merit reporting.

1. Group like technologies in presentation modules.

2. Refine the presentations concerning the technology, particularly where there may have been a desire to hear different presentations occurring in nearly the same time period. 
3. Provide an executive summary in advance which would indicate the name of the presenter, the laboratory represented, and a short title of the technology to be presented.

4. Provide more advance notice concerning the technology scheduling and location. It was observed overall that the Transfair is a good way to cover a lot of territory at one time, whereas an attendee would occasionally want to be in two places at one time even at the Transfair itself the one-on-one Transfair format provided a recovery mechanism. It was obviously a good combination.

5. The Navy Transfair concept should be employed by the other military services.

Having understood the structure of the Transfair, the consideration will now be given to appreciation of what was attained. There were the immediate results of the Transfair information and exposure to the audience and the probability of acquiring patents for development into the commercial market. But there is a longer range appreciation which will be addressed further in this report. 
It is particularly significant to observe what has occurred since 1989 that brings greater focus to the emphasis of the real significance of the Transfair. There have been three major political, military, and historical happenings since 1989. The most significant political event is the downfall of communism and the restructuring of the nations of Europe and of Asia.

Second, Desert Storm exhibited technology in its most advanced military application which highlighted the technological expertise of the United States. This expertise was, and is, not an unknown factor but had not, prior to that time, been so clearly demonstrated to all the world in the television format on the report of the war. There is no question that in addition to the victory itself in Desert Storm the satisfaction of the performance of American technology brought a sense of pride and accomplishment to all who participated and observed.

And the third event has been and is continuing to be the reformation that is occurring in the military services through the reductions in defense spending, the reassessment of a threat and the reduced requirements expectation. Captured in the latter category is the 
restructuring of the defense laboratories, not just the Navy laboratories but all defense laboratories, and the possibilities of realignment within the entire national laboratory system.

From an industrial base perspective, in order for the United States to remain globally competitive it goes without question that the laboratory system which has served the nation so ably in the last six decades, specifically as a national resource of technology development, must be maintained if the country is to sustain its forte on the world scene as the finest technology basin on the planet. In the competition for economic stability and survival which has seen facilities for production in the United States diminished because of competition from other countries in the labor market, the United states maintains its leadership with technology. That is what the country must produce and must export to the world.

It is obvious that resources will be required to maintain the laboratory system even with the lessened demands and the requirements for military technologies. Research, however, in defense applications will continue 
irregardless, some of it for pure research motives, and some of it for specific demands by the military services to satisfy the response to current and future threats. We cannot overlook that necessity. But what the events of the past three years have presented to us are the opportunities that lie in the non-defense area for exportation of technology which has dual application.

While not a subject of this report and of the Transfair directly, if one would investigate research that is likely occurring in the defense and the national lab system at this very time, very interesting developments would probably be exposed which would indicate application to the needs and the quality of life perhaps of individuals, of groups, of organizations, the environment, and humanity itself. It is those technologies which may be obscured because of the lack of demand on the military scene in the absence of a requirement or, second, a non-appreciation for the applicability to the commercial production, and thirdly, to a lack of a full understanding by the developer as to the significance of the technology that has been brought forth either by design or happenstance as a spinoff from some other activity. 
It is here that the Transfair and the concept of transferring that technology from those laboratories has an unparalleled expectation for the entrepreneur who wishes to export the technology as well as for the research scientist who has developed the technology. In the interchange of the Transfair environment, the synergism of inventor with a commercial business person might be the very spark that can launch a development not only of unexpected rewards but of very gratifying compensation.

The value of the Transfair to the individual innovator could bring monetary returns, prestige, acclaim, and perhaps even a place in history and certainly the representation of the laboratories and a salute to the environment in which the innovator was able to perform would be salutary. The impact on the industry attendees at the Navy Domestic Transfair was not only that of knowledge of new inventions, or of inventions of which they were unaware, but it was a knowledge of how to go about acquiring this technology for application to the commercial sector and the possibility of monetary rewards.

The greater reward come from the insights into the laboratory and industry cooperation to promote the 
national resource of the laboratory to the benefit of the quality of life not of few but of many. The impact for the industrial technology base is potentially infinite in scope for it will continue to feed on itself, providing the impetus for continued development and encouragement to scientists and innovators to continue their search in building the "better mousetrap." Far beyond the technology base is the opportunity to begin to regain the production base of the United States.

Whereas this may be a very long term arrangement, the very fact that the technology base is receiving such attention and demand, with the expectation of commercial exportation, can lead only to the increased development of facilities to build those things which will now become marketable products. It does not mean that we wait for a formal national industrial policy. It does require an appreciation on behalf of national leaders, particularly in the Congress, in both the Senate and the House, where the technology committees must be enlisted to give their support to the very basic issue of technology exportation in the national interest and what that technology exportation can mean to the economic health of the nation 
as a whole.

It was not fully appreciated in the instance of a Transfair event itself that the ramifications could be so great. The reasons stated above of the historical and political events which have occurred in the three years since the Transfair itself was conducted have elevated the significance of the Transfair concept. One could not have predicted with any accuracy at that time that the conditions for general commercial development would be so provocative in the transfer of technology from our national laboratory resources.

What now must be done is to reinvestigate the technologies that are available for transfer that have not been exposed to date. This goes far beyond the individual innovator and the exportation on whatever commercial plane certain technology may be promoted. It goes to the far more significant anticipation of a group of technologies that could be applied, by sector, for whatever needs there may be to solve national and even international problems. The importance here must not be lost on the promotion of technology from just one laboratory source. What has occurred in the laboratory/industry cooperation is 
not just a vertical integration of laboratory-produced technology with the private sector business exportation but, further, the synergism that will be gained through the sharing across the industrial sector back into other labs. There is no naivete in the understanding that there is a sharing of technology amongst labs. At the same time, there is appreciation for some competitiveness by labs. Furthermore, there is no doubt ignorance on behalf of technology developments out of sheer time and space realities. Having the industrial sector exposed in a Transfair arrangement will provide a possible pollinization to other laboratories that might not have been acquired otherwise. The sum of such technology sharing can possibly experience greater leverage not only in the marketplace but also in the technology leadership of the nation.

There should be little concern for the escape of technology beyond the borders of the United States. It has been said that technology has a definitive shelf life and that given sufficient time others will discover and develop that same technology anyway. Therefore, it is a constant upgrading, refining, expanding, and exporting of technology that is being developed at any given time. As long as one 
remains in the lead, there is no danger that the most recently developed technology will be taken away before it can be appropriately exploited on behalf of the original developer. By that time, new ideas have borne fruit, new innovations are being put to the practical test of development and production and new levels of technology are emerging.

The seed of the Navy Transfair experience has been planted and now it requires appropriate cultivation within government at all laboratory levels. This experience is far beyond the Department of Defense. The potential gain for the private sector and the consumer is not easily quantified because the results will be contingent on marketing and promotion even after agreements of technology transfer have been concluded. Obviously, consumer acceptance will play a distinct role, yet, the availability of the technology for general distribution is the key matter.

It is here that the American Defense Preparedness Association can be the catalyst to prod, first of all the Department of Defense laboratory system to include all military services, then to expand the concept to other 
Departments. In so doing, the Association can utilize its Legislative Affairs arm to gain recognition for public law support as well as Congressional influence in promoting economic stimulus.

The Navy Transfair opened the door for a new attitude in government/industry cooperation. The nation is the beneficiary. 


\section{TRANSFAIR PARTICIPANTS}

\section{TRANSFAIR I}

Tucedas

29 Anguat 1909

$1600-1800$

Bolling NWC

Czyryea, DTRC

Dallek, NUSC

Evans, NSWC

LCDR Melschman, NAMRL

Ford, DTRC

Goodfrlend, Edge

Ilammond, NOSC

Ilartley (Miller), NUSC

Ilodgson, NAC

Koslowsk, NATC

Mooreroln, NUSC

Savage, NSWC

Spadąora, NADC

stimey, NORDA

Thornton, NATC

Trias, NOSC

Turcotte, NORDA

Vernon, NSWC

TRANSFAIR m

\section{Wednesday \\ 30 August 1989 \\ 1400-1600}

Chase, NUWES

Clement, NRL

Cushman, NAMRL

Czyryca, DTRC

Dallek, NSWC

Fay, NUSC

LCDR Flelschman, NAMRL

IIartley, NUSC

llodgson, NAC

Koslowskj, NATC

LT Miller, ND\&STC

Moorcroln, NUSC

Savage, NSWC

Skruch, DTRC

Stiney, NORDA

Tarr, NSWC

Trias, NOSC

Vernon, NSWC

Wilhelml, DTRC

\section{TRANSTAIR I}

\author{
Wodneaday \\ 30 August 1989 \\ 1030-1230
}

Chase, NUWES

Clement, NRL

Cushing, NAMRL

Deatherage, NSWC

Evans, NSWC

Fay, NUSC

Grimth, NRL

IJartley, NUSC

Jorgensen, NAC

KIngston, NATC

Mapes, NUSC

LT Miller, ND\&STC

Peler, NSWC

Price, NRL

Reed, NWC

Skruch, DTRC

Turr, NSWC

Vernon, NSWC

Wilhelml, DTRC

TRANSFAIR IV

Thurseday

31 August 1989

$1400-1600$

Bolling, NWC

Deatherage, NSWC

Evans, NSWC

Ford, DTRC

Goodfriend, Edge

Grimth, NRL

Ilammond, NOSC

Jorgensen, NAC

Kingston, NA'TC

Mapes, NUSC

Nakonechny, D'TRC

Peler, NSWC

Price, NRL

Reed, NWC

Spadafora, NAI)C

Thornton, NA'C

Turcotte, NORI)A

\section{PLUS ALL EXHIBITORS}


A Scheiner-Principle Pocket Optometer for Self Evaluation and Biofeedback Accommodation Training

William B. Cushman. .

Naval Aerospace Medical Research Laboratory

Electromagnetic Energy for the On-Sile Treatment of Severe Hypothermia

Richard G. Olsen

Naval Aerospace Medical Research Laboratory

Method and Apparatus for Treatment of Hypothermia

by Electromagnetic Energy

Richard G. Olsen

Naval Aerospace Medical Research Laboratory

RF Rewarming System

Richard G. Olsen

Naval Aerospace Medical Research Laboratory

Computer Control Unit Emulator CCU/E

Michelle L. Kozlowski

Naval Air Test Center

High-Strength, Low-Alloy Steels for Ship Construction

Ernest J. Czyryca

David Taylor Research Center

Surface Efrect Ship (SES) Technology

A. G. Ford

David Taylor Research Cenier

Single-Screw Air Compressors

Harry Skrunch

David Taylor Research Center

Single-Screw Pump

Harry Skrunch

David Tuylor Research Center

Variabla Capacity Centrifugal Pump

Harry Skrunch

David Taylor Research Center

Composite Materials for Ship Machinery Applications

George F. Wilhelmi

David Taylor Research Cenier

Design and Testing of a Balanced Air Regulator for Deep Sen

and Scuba Divers

LT Benjamin K. Miller, Jr., USN

Nayy Diving Salvage Training Center 
High-Definition, Video-Rate, Laser-Addressed Liquid-Crystal

Light-Valve Projection Display

John A. Trias

Naval Ocean Systems Center

Real-Time, High-Resolution, 3-D Large-Screen Display Using

Laser-Activated Liquid-Crystal Light Valves

John A. Trias

Naval Ocean Systcmss Center

Real-Time, Ultra-High-Resolution Image Projection Display Using

Laser-Addressed Liquid-Crystal Light Valve

John A. Trias

Naval Occan Systems Center

Method and Apparatus for the Detection of Toxicants

Patrick J. Hannan, Arthur V. Stiffey, N. Lynn Jarvis, and Henry Wohltjen

Naval Oceanographic and Atmosspheric Research Laboratory

NRL Muoropolymer Inventions, Materials, Uses, and Prospective Uses James R. Griffith

Naval Research Laboratory

Holographic Optical Elements for Laser Diodes

Anne E. Clement

Naval Rescarch Laboratory

Technological Opportunitics in Biomolecular Enginecring

- Ronald R. Price

Nevial Research Laboraiory

Silver Oxide (AgO) Cathode

Steven Dallek

Naval Surface Warfure Center

Data Acquisition and Reduction Processor (DARP) for AN/UYK-43(V)

Performance Monitor Interface (PMI)

James Deatherage

Naval Surface Warfare Center

Application of Global Positioning System Satellites to Deternine Earth's

Gravity and Platform Orientation

Alan G. Evans

Nenval Surface Warfare Center 
(iPS-Aided Gravimetry at $30 \mathrm{~km}$ Altitude from a Balloon-Borne Platform

Andrew R. Luzarewicz

Air Force Geophysics Laboratory

Alan G. Evans

Nenval Surface Warfure Center

CMSTOOL Version 1.2

Michuel Peeler.

Naval Surface Warfare Center

Magnetustrictive Sensors and Actuators

H.T. Savage and Arthur E. Clark

Naval Surface Warfare Center

Method of Measuring Magnetic Efrects Due to Eddy Currents

Paulo B. Tarr

Naval Surface Warfare Center

Nondestructive Inspection by Eddy Current Methods of Carbon

Fiber Reinforced Composites and Metals

Susan N. Vernon

Naval Surface Warfare Center

Optimum Flow Noise Cancelling Hydrophone Module

John W. Fay

Nawal Undenwater Systems Center

Teletypewriter Loop Switching Matrix

Robert R. Hartley and Joseph A. Konrad

Naval Underwater Systems Center

Magnetic Field Transducer Systems

Theodore J. Mapes

Naval Underwater Systems Center

Blectronic Noise-Reducing System

Harry B. Miller

Naval Undenvaler Systems Center

Symmetric Waveguide Junction Combiner

Donald R. Bowling

Naval Weaponss Center

Fire Extinguishing Material

Russell Reed

Naval Weapons Cenier

Improved Booster Explosive

Russell Reed

Naval Weapons Center 


\section{Tuesday, 29 August 1989 \\ 1030 - 1230}

P1 - Moderator: Robert Heidenreich, NSWC outgoing ORTA

PIA - Mike Peler, NSWC

"CMS-2 Software Matrix Tool"

P1B - Bob Kingston, NATC

"Video Recording Multiplexer-Demultiplexer"

P1C - Dr. Russell Reed, NWC

"Fire Extinguishing Material"

P1D - Dr, James Grimth, NRL "NRL Fluoro-Polymer Inventions/Materials"

P2 - Moderator: Dan Watters, NATC ORTA

P2A - Susan Vernon, NSWC

"Method \& Device for Measuring Resistivity"

P2B - Dr. William Cushman, NAMRL "Pocket Optometer to Reduce Night Myopin"

P2C : Harry Skruch, DTRC

"Navy Compressor and Pump Technology"

P2D - John W. Fay, NUSC

"Optimum Flow Noise Canceling Hydrophone Module" 


\section{Tuesday, 29 August 1989 \\ 1330 - 1530}

P3 - Moderntor: Larng Halbig, NAC ORTA

P3A - Paulo Tarr, NSWC

"Method of Eddy Current Depth Measurement"

P3B - Roger Erickson, Omce of the Corporate Counsel, OCNR "The Navy Patent System"

P3C - George Wilhelmi, DTRC "Composite Materials"

P3D - Anne Clement, NRL "Holographic Optical Elements for Laser Diodes"

P4 - Moderator: Charles Newmyer, NWC ORTA

P4A - Susan Vernon, NSWC "Device for Inspection of Materials by Eddy Current"

P4B - LT B. K. Miller, USN, ND\&STC "Design and Testing of a Balanced Air Regulator for Deep Sea and SCUBA Divers"

P4C - Jay Chase, NUWEC "Tracking and Telemetry System for Severe Multipath Acoustic Channels"

P4D - Robert D. Hartley, NUSC "Teletypewriter Loop Switching Matrix" 


\section{Wednesday, 30 August 1989 \\ 0800 - 1000}

P5 - Moderator: Lany Halbig, NAC ORTA

P5A. - Dr. Steven Dallek, NSWC "Silver Oxide ( $\mathrm{AgO}_{\mathrm{g}} \mathrm{O}$ Cathode"

P5B - Michelle Koslowskj, NATC "Computer-Controlled Unit Evaluator"

P5C - Arthur L. Moorcron, NUSC "Precise Bearing Support Ditherer with Piezoelectric Drive"

P5D - Bruce Hodgson, NAC "Generating Optical Photo Masks"

P6 - Moderator: Margaret McNamara, NUSC ORTA

P6A - Don Bolling, NWC "Symmetric Turnstlle Power Combiner"

P6B - Ernest Czyryca, DTRC "High-strength, Low-alloy (IISLA) Steels"

P6C - Arthur V. Stimey, NORDA "Solid State Photometer Circuit"

P6D - Robert D. Hartley, NUSC (for Harry B. Miller) "Electronic Noise Reducing System"

P7 - Moderator: Diane Jackson, NOSC ORTA staff member

P7A - Susan Vernon, NSWC "Method of Measuring Magnetic Erects Due to Eddy Currents"

P7B - LCDR Thomas Fleischman, USN, NAMRL (for Dr. R. G. Olson) "RF Rewarming System"

P7C and P7D - I. J. Trias, NOSC "Real-Time, Ultra-high Resolution Image Projection Display using Laser-addressed, Liquid Crystal Light Values" 


\section{Thursday, 31 August 1989 \\ 0800 - 1000}

P8 - Moderator: Dr. Norman Brown, Technology Targeting, Inc.

P8A - Mel Goodfriend, Edge Technologies, Inc.

Terfenol-D: A Success Story with a Navy Patent on

a Magnetostrictive Alloy"

P8B - Ms. Ding Thornton, NATC "Computer-aided Design of Digital Filtering/ Smothering Schemes"

P8C - Dr. Howard Savage, NSWC "Magnetostrictive Sensors and Actuators"

P8D - Arthur V. Stimey; NORDA "Method \& Apparatus for Detection of Toxicants" "Method for Evaluating Anti-Fouling Paints"

P9 - Moderator: Dan Watters, NATC ORTA

P9A - Dr. Alan Evans, NSWC "Gravity Using Global Positioning System"

P9B - Steve Spadafora, NADC "Aerospace Materials Technology"

P9C - Allan Ford, DTRC "Surface Errect Ship (SES) Technology"

P9D - R. E Hammond, NOSC "Method of Curing Patches on Contoured Surfaces" 


\section{Thursday, 31 August 1989 \\ 1030 - 1230}

P10 - Moderator: Diana Jackson, NOSC

P10A - John Gibson, NASA's COSMIC Omice at the University of Georgin "NASA's Computer Sontware and Information Center"

P10B - Basil Nakonechny, DTRC ORTA "DTRC Facilities and Capabilities"

P10C - Mary Ellen Turcotte, NORDA "NORDA Technology"

P10D : Ron Price, NRL "Technological Opportunities in Biomolecular Engineering"

P11 - Moderator. Dr. Norman Brown, Technology Targeting, Inc.

P11A - Jamies Deatherage, NSWC

. "Data Acquisition and Reduction Processor System"

P11B - Theodore J. Mapes, NUSC

"Magnetic Field Transducer Systems"

P11C - Dr. Russell Reed, NWC

"Improved Booster Explosive"

P11D - Diane Sullivan, NSWC, Editor, Navy Domestic Technology Transfer FACT SHEET

"The Navy Domestic Technology Transfer FACT SHEET"

P12 - Moderator: Bob Heidenreich, NSWC

P12A - Margaret McNamara, Vice Chair, Federal Laboratory Consortium for Technology Transfer

"The FLC and How it Grew"

P12B - Keith Schneider, Mead Data Systems

"Lexus/Nexus and Navy Patents"

P12C - Dr. Alan Evans, NSWC

"Method of Determining the Direction of a Moving Platform"

P12D - Elden Jorgensen, NAC "T-Slot Sheave" (a mechanical pulley) 


\title{
A Scheiner-Principle Pocket Optometer for Self Evaluation and Biofeedback Accommodation Training
}

\author{
William B. Cushman \\ Naval Aerospace Medical Research Laboratory
}

\begin{abstract}
Most humans tend toward myopia when presented with a visual field without sufficient detail to stimulate focusing mechanism. This means that a pilot flying in darkness, or in an "empry field" such as empty sky, will be likely to focus nearer the windscreen than at the optical infinity required to focus on visual targets of probable interest. Biofeedback training to counter this problem has been limited in practical application by expensive and cumbersome instrumentation.
\end{abstract}

A Scheiner-principle optometer has been developed for self-evaluation of accommodative state and biofeedback training. The specific advantages of the new invention over earlier optometers are: (a) simplicity of design; (b) handheld, portable implementation; (c) light weight; (d) small size; (e) low manufacturing cost; $(f)$ the use of a monochromatic light source to eliminate the effects of chromatic aberrations in the subject's eye; and $(g)$ effectiveness as a training aid.

Four prototypes of the pocket optometer have been built and were used to implement biofeedback training to correct night myopia in 12 Navy aviation candidates. All subjects were emmetropic in full light. Training was limited in duration because of the transient nature of subject availability but was reasonably successful in 10 out of the 12 cases.

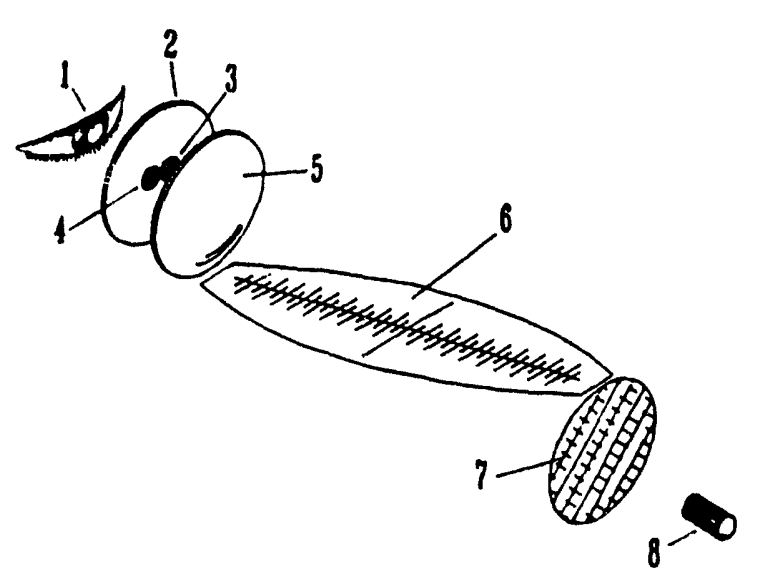

Schematic of the pocket optometer. [1] subject's eye; [2] pinhole aperture stop plate; [3] and [4] pinhole apertures; [5] Badal lens; [6] scale: [7] diffuser; [8] light emitting diodide. 


\title{
Electromagnetic Energy for the On-Site Treatment of Severe Hypothermia
}

\author{
Richard G. Oisen \\ Naval Aerospace Medical Research Laboratory
}

Navy and Marine Corps personnel who become the victims of severe hypothermia need prompt, active rewarming. Ideally, a rewarming device would warm the heart and central vasculature first and could be used in remote locations such as at battalion aid stations, aboard ships, or in rescue vehicles. Since 1979, a project to incorporate electromagnetic energy as a rewarming modality has been under way at the Naval Aerospace Medical Research Laboratory (NAMRL). Effort has centered around the use of a torso-mounted radio frequency (RF) coil system, and the initial experiments were conducted with thesus monkey subjects and tissue-equivalent human models. The early NAMRL experiments compared RF energy with a conventional heating pad for rewarming effectiveness, and serum enzyme analysis was used to assess internal injury. Initial results showed that RF energy could be safely applied at rates of 5 to $10 \mathrm{~W} / \mathrm{kg}$ or three to six times that of basal metabolic rate (BMR) in monkeys; RF rewarming was, moreover, twice as fast as heating pad rewarming. A man-size RF coil system was then constructed and dosimetrically tested. The full-size coil exhibited both surface and deep heating. Recently, at the Naval Medical Research Institute, the coil system was tested with human volunteers who were rendered mildly hypothermic by cold water immersion. At an RF dose rate of approximately $2 \mathrm{~W} / \mathrm{kg}$, core rewarming was typically accomplished within 1 hour, and the characteristic immersion-induced temperature afterdrop was greatly reduced. The RF coil system has great potential for hypothermia resuscitation although further development is necessary to produce a device that is most useful to the Navy. The RF rewarming coil system has been shown to be effective in raising the body's core temperature in many animal experiments and in a preliminary study with human subjects. Although the initial development effort has concentrated on use in the military operational environment, many other clinical applications exist such as postsurgical rewarming and emergency room resuscitation. 


\title{
Method and Apparatus for Treatment of Hypothermia by Electromagnetic Energy
}

\author{
Richard G. Olsen \\ Naval Aerospace Medical Research Laboratory
}

This apparatus and method rewarms hypothermia victims by using mutually inductive first and second helical coils supported in spaced relation around a subject's torso, the combination of coils and subject having resonant frequency in the 2 to $20 \mathrm{MHz}$ range. An automatic tuner couples a radio frequency generator to energize the coils at the resonant frequency. A portable version uses flexible coils on an insulating and spacing jacket having a zippered opening with conductive teeth to complete coil turns.

Patent Number 4,685,462

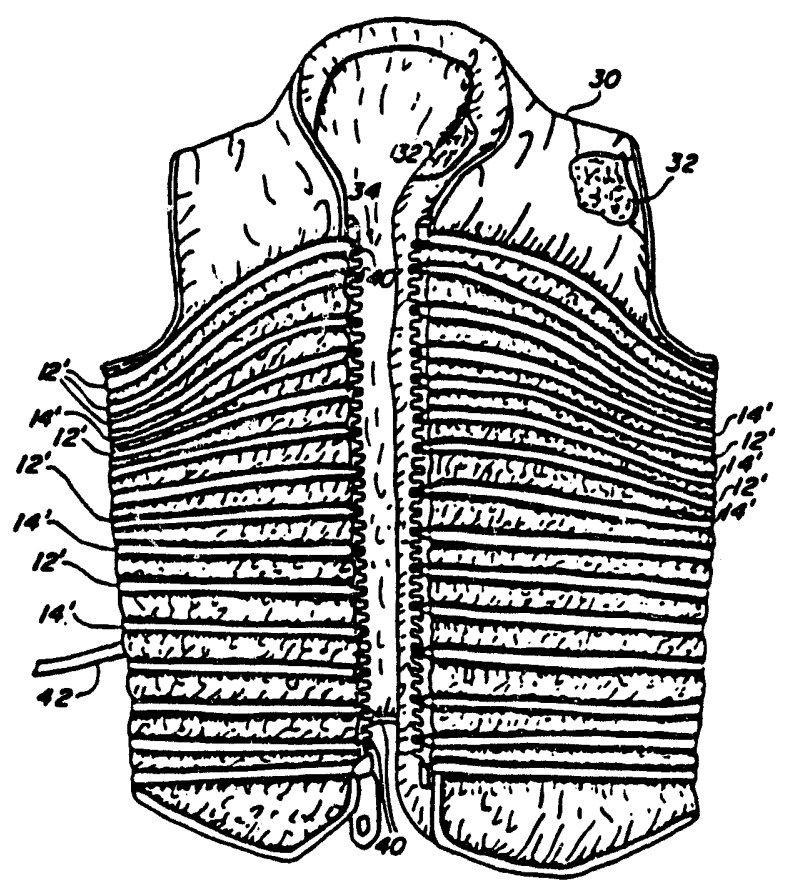

Front elevational view of a flexible coil and supporn structure for first-aid application to a hypothermia victim 


\title{
RF Rewarming System
}

\author{
Richard G. Olsen \\ Naval Aerospace Medical Research Laboratory
}

The environmental factor of cold water is known to be a prime cause of impaired diver performance. Decrements in dexterity typically occur at finger temperatures below about $15^{\circ} \mathrm{C}$. Purely passive thermal hand protection is self defeating because it necessitates the use of bulky gloves or mittens and precludes the full usefulness of the hands.

To date, active thermal protection of the extremities has involved surface-applied heat such as warm water or direct electrical current to heat a resistive wire. Surface-applied heating methods tend to be inefficient in cold water because of large conductive heat losses and because of the thermal limitations of skin burning. Radio frequency (RF) energy has received little attention in this area even though the deep-heating properties of helical RF coils for tumor therapy and hypothermia resuscitation have been demonstrated. A system that deposits energy within the volume of an extremity rather than at its surface might be efficient enough to maintain a diver's manual dexterity without the need for a prohibitively large and bulky electrical power source. This study was, therefore, conducted to investigate the feasibility of using a resonant RF applicator system to efficiently provide warmth to a diver's extremities. The results were sufficiently encouraging to suggest that direct RF heating of the limbs could have a wide range of applications.

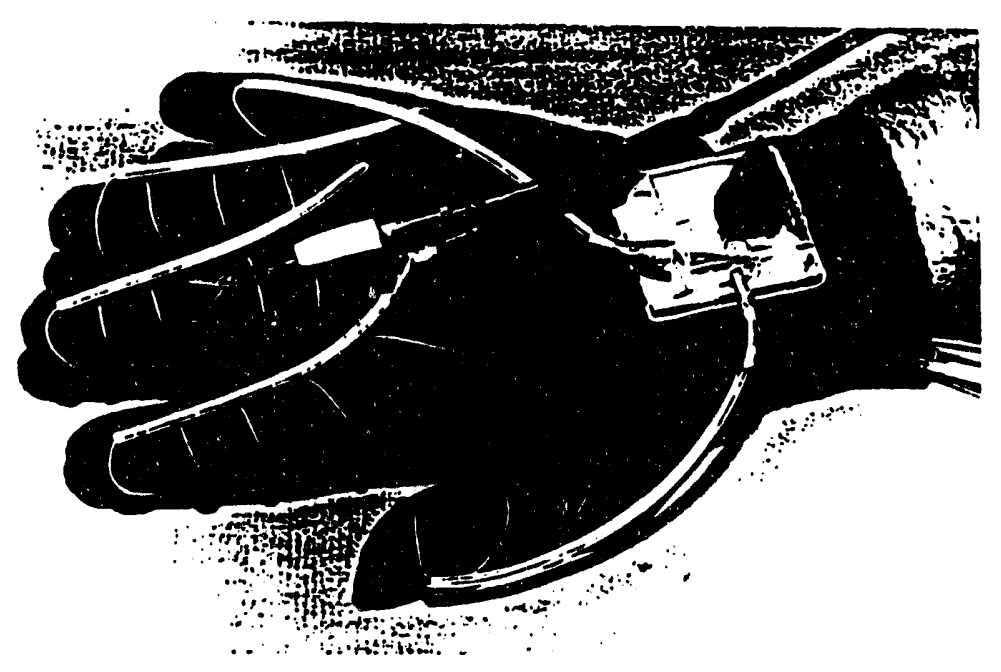

The RF hand warming coil was a series connection of finger coils attached to a cotton work glove 


\title{
Computer Control Unit Emulator CCU/E
}

\author{
Michelle L. Kozlowski \\ Naval Air Test Center
}

The Computer Control Unit Emulator (CCU/E) is a hardware/software package used for software development and debug as well as maintenance support for the Navy's AN/AYK-14(V) Standard Airborne Computer. The CCU/E allows AYK-14 program loading memory examination, breakpoint setting, and control of program execution. The package is available for DEC VAX systems running under VMS as well as IBM PCs and compatibles.

In 1981, NATC developed the emulator as a support tool for automated AYK-14 T\&E. It was rewritten in Pascal in 1984. It enhanced the capabilities of the original CDC CCU by

- targeting to multiuser hosts (DEC VAX),

- increasing the functional command set, and

- providing control by another VMS process.

The CCU/E was initially targeted to the IBM PC in 1988. It is continuously being updated and enhanced to meet AYK-14 user software development needs.

The CCU/E has become the de facto standard used through the Navy and industry. More than 150 systems are in use at more than 50 different user sites:

- NATC, NAC, NWC, NSWC, PNTC, NADC, NASA

- Grumman, Norden, Litton, Lockheed, Honeywell, CDC, Unisys

- RNZ Air Force, UK Air Force, Canadian Air Force

The CCU/E is used in a wide range of programs in many different support roles:

- Software development F-14D, A-6G, E-2C, EA-6B, V-22, EP-3C, MK-50, ALS-N

- Software test and maintenance F-18, AV-88, F-14D, EA-6B, E-2C, V-22, ALS/N

- AYK-14 hardware test and maintenance NATC, NAC, NADEP Norfolk. 


\title{
High-Strength, Low-Alloy Steels for Ship Construction
}

\author{
Ernest j. Czyryca \\ David Taylor Research Center
}

Modern ship design in the past decade shows a continuing trend of increased use of high-strength, low-alloy (HSLA) steel plate for weight reduction, increased payload, and increased fuel economy. Ship structures are subjected to a complex spectrum of dynamic loadings and stresses built into the hull during fabrication, and they must operate in both tropical and arctic seas. The structural integrity of the hull must be assured in these severe operational environments. The structural steels and welding materials used in hull fabrication must demonstrate high fracture toughness for these extreme service conditions.

The high-strength steels traditionally used in Navy ship construction, HY-80 and HY-100, were certified to meet these requirements. However, the welding of the HY-series steels requires a number of fabrication controls to prevent cracking. These controls have resulted in high fabrication costs and have limited the commercial application of the HY-series steels. The Navy initiated the HSLA steels research and development program at David Taylor Research Center with a goal of reducing shipbuilding costs. The technical objective was, and remains, the development and certification of high-strength steels and welding consumables, lessened parameter controls (particularly preheat), high strength, high toughness, and high-quality weldments.

In 1984, HSLA-80 steel (MIL-S-24645), based on ASTM A710 Grade A steel, was certified for use in ship construction after an extensive program demonstrated that the low-carbon, copper precipitation strengthened steels met the performance requirements of $\mathrm{HY}-80$ steel but were readily weldable with no preheat. Lower fabrication costs and higher productivity in construction were the benefits realized when HSLA-80 was substituted for HY- 80 . HSLA-80 steel is a primary structural steel used in the current construction of cruisers and destroyers.

Following the successful HSLA-80 program, an alloy development and qualification program began in 1985, which resulted in HSLA-100 steel (MIL-S-24645A). HSLA-100 is also a low-carbon, copper precipitation strengthened steel, meeting the strength and toughness of $\mathrm{HY}-100$ steel but weldable with lower preheat. HSLA-100 was certified for use in ship structures by the Navy in early 1989. HSLA-100 will be used as a replacement for HY-100 to gain significant fabrication cost reductions in new construction over a wide range of plate gages.

Although specifically developed for military construction, these weldable, high-strength steels can be used to advantage in non-DoD and civilian fabrication, where strength and low-temperature fracture toughness are required. Certainly, arctic-operating ships and offshore drill rigs, transmission towers, heavy construction and earthmoving vehicles, and nuclear containment/transportation vessels are examples where the HSLA steel technology can be applied. 


\title{
Surface Effect Ship (SES) Technology
}

\author{
A. G. Ford \\ David Taylor Research Center
}

The Surface Effect Ship (SES) technology began in 1960, funded by the Foundation Research Program at the Naval Air Development Center, Warminster, PA. At that time Ground Effect Machines (GEMs) had large "daylight gaps" of blown air between their hard structure and the ground, and a large penalty resulted from larger (realistic) craft weights. The Captured Air Bubble Vehicle envisioned a captive region of air retained on the sides by sidewalls, and fore and aft by end seals that moved up and down in response to waves. This allowed realistic craft weights without incurring excessive air system power penalties. By the time a U.S. patent was issued on this concept in 1964, the Navy's XR-1 experimental research craft had been designed and built and was in operation. In 1965, the David Taylor Research Center (DTRC) accepted technical leadership of this effort.

By 1967, the Maritime Administration study "Surface Effect Ships for Ocean Commerce" had adopted the foregoing concept, and together with the Navy, was in the process of setting up an SES management team. This team ultimately the Navy's SES Project Management Office (PMS-304), built the SES-100A, a waterjet propelled 100-ton SES testcraft, and the SES-100B, propelled by semisubmerged supercavitating propellers. This latter 100-ton SES achieved a 92-knot speed and a world record. A 3000-ton "3KSES," a 70-to 80-knot ASW frigate, was also designed.

A parallel SES development in the early 1970s, funded by the Independent Exploratory Development (IED) Program at DTRC, was the high length-to-beam ratio SES concept. This concept promises significantly reduced power for SESs, of reasonably high speed (e.g. 50 to 55 knots at frigate size), less reduction in speed in higher sea states, and improved seakeeping characteristics. This IED program led to a better understanding of this class of SESs through predictions of high L/B SES drag and powering characteristics for calm water and in waves and verification of these characteristics through SES model tests in DTRC towing tanks. These tests addressed not only drag and powering, but also stability, structural loads, and designs that resulted in good seakeeping characteristics. The XR-5-the experimental SES research manned testcraft-and the USN DTRC SES-200 were designed, built, and evaluated as part of this program.

In the United States, Textron Marine, Inc., of New Orleans has built a number of SESs for commercial use, for the U.S. Coast Guard for its drug interdiction duty in Key West, Florida, and for the U.S. Navy. The major construction of commercial SESs (about $130 \mathrm{craft}$ ) has been in England, principally for export. Norway has recently built a number of SESs for Norwegian coastline SES ferry operations and has also exported some craft. A group of mine warfare ships, based on this ferry 
experience. is now in the design and construction phase in Norway. Sweden has also built several SES ferries. Germany is now doing design verification of a 700-ton fast SES testcraft (Eprobungsboot Schncll). The French Navy is building the NES-200, a 200-ton SES testcraft, with an ASW frigate planned in the future. The Spanish have a 30- to 50-ton SES testcraft in fabrication and intend to build an SES fast patrol boat in the future. There is an Italian plan similar to that of Spain.

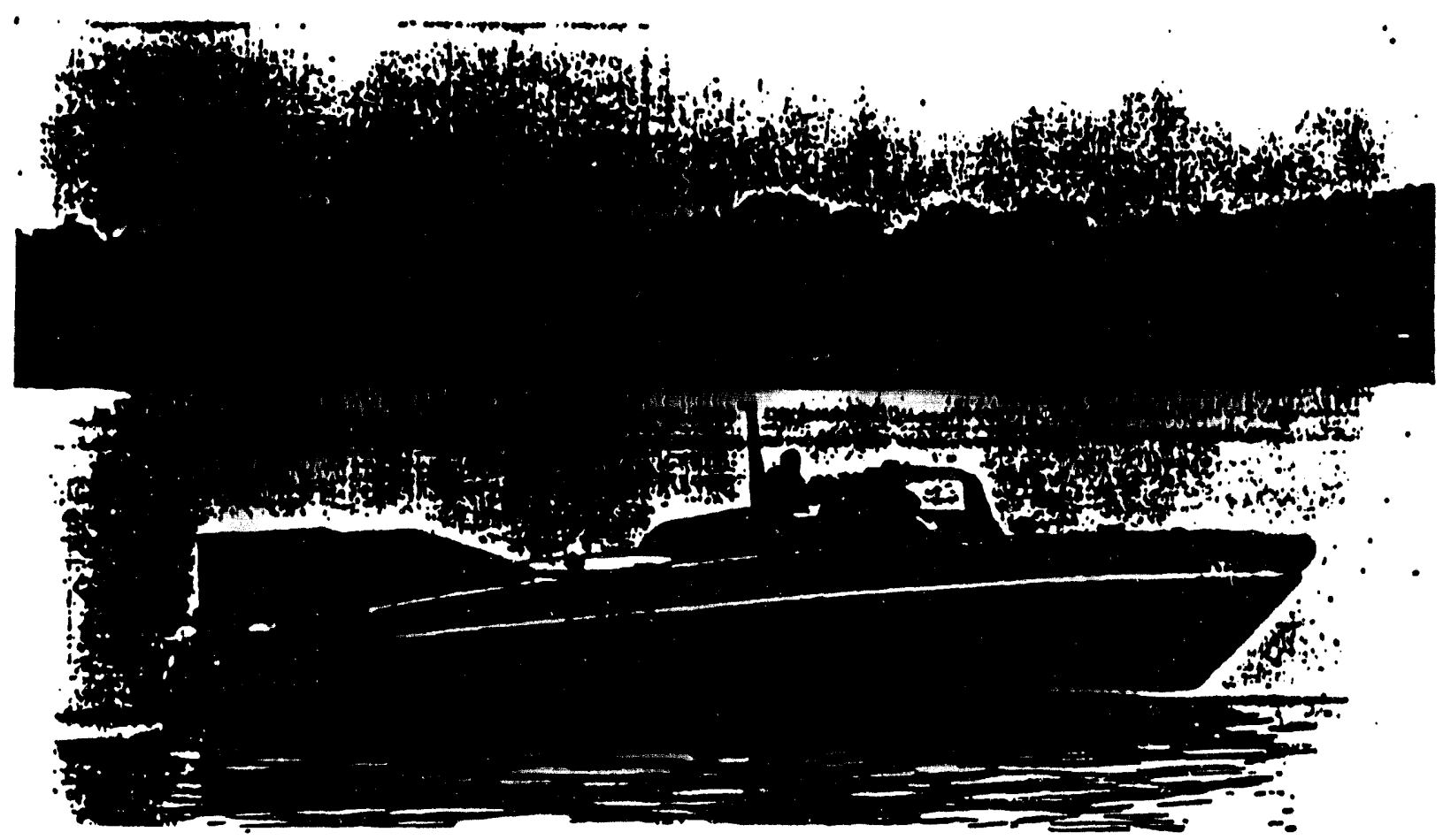

XR-1 SES testcraft undergoing trials in 1964 


\title{
Single-Screw Air Compressors
}

\author{
Harry Skrunch \\ David Taylor Research Center
}

The Navy has developed a single-screw air compressor design that uses water to cool and seal the compressor processor and lubricate journal-type bearings. The grooved cylindrical mainrotor is engaged by two planar gaterotors to produce six compressions per revolution. The unique groove shapes can be manufactured on programmed five-axis mills or by machine tools available under licensing agreements from the French inventor. (Most patents have expired.) A $150 \mathrm{lb} / \mathrm{in} .{ }^{2}, 200$ std $\mathrm{ft}^{3} / \mathrm{min}$ design has been standardized for shipboard applications. Research has been accomplished at pressures as high as $3000 \mathrm{lb} / \mathrm{in}^{2}$.

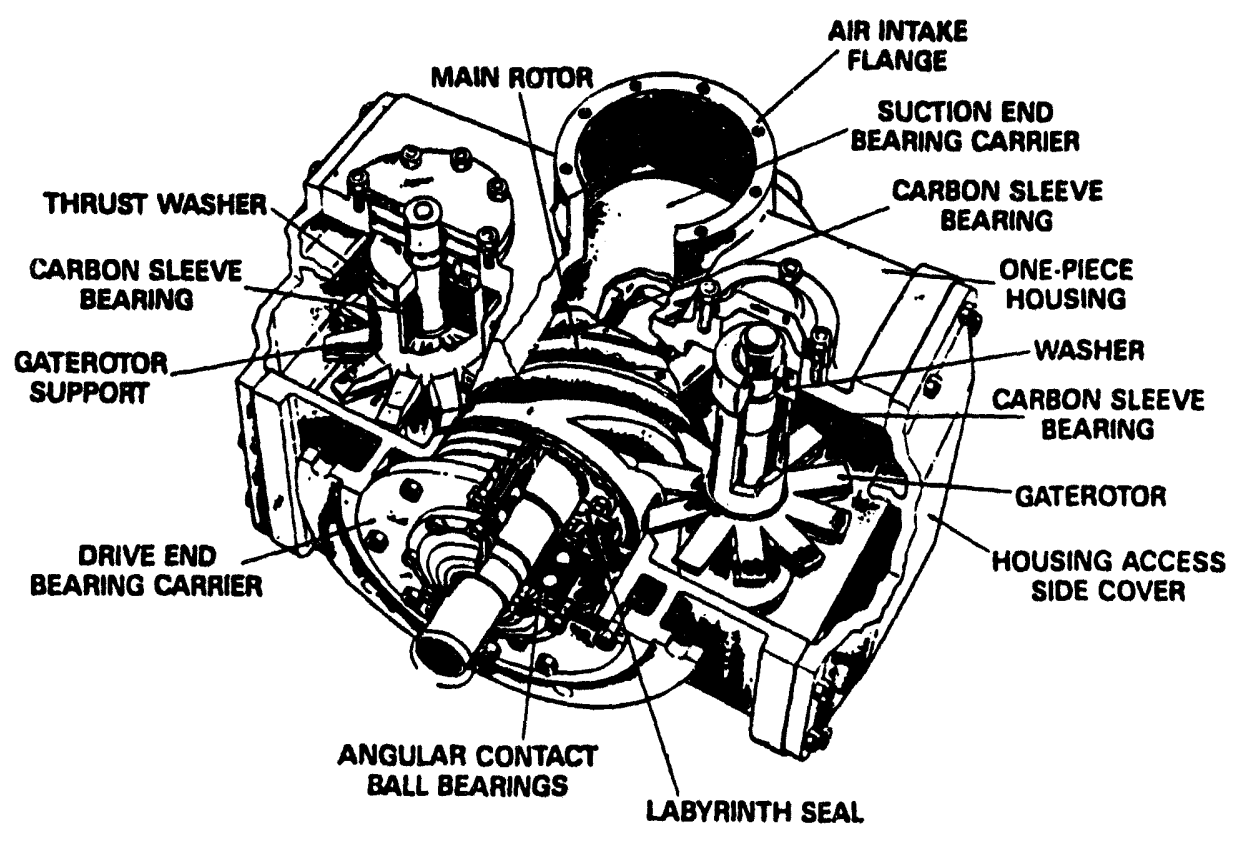

Water-lubricated si'ngle-screw compressor 


\section{Single-Screw Pump}

Harry Skrunch

David Taylor Research Center

A screw-type positive displacement pump has been developed that can pump low-viscosity fluids. The pump embodies a mainrotor with two helical grooves that mesh with two cylindrical, toothed gaterotors to form multiple constant-volume pockets that sweep along the mainrotor. This design avoids the need for discharge ports and provides a large suction entrance. A volumetric efficiency of $63 \%$ has been demonstrated that pumps diesel fuel at $100 \mathrm{lb} / \mathrm{in}^{2}$. The meshing rotor surfaces have been machined on five-axis programmable mills and by using abrasive coatings. It is projected that aqueous solutions can be pumped by using journal bearings of carbon against silicon carbide.

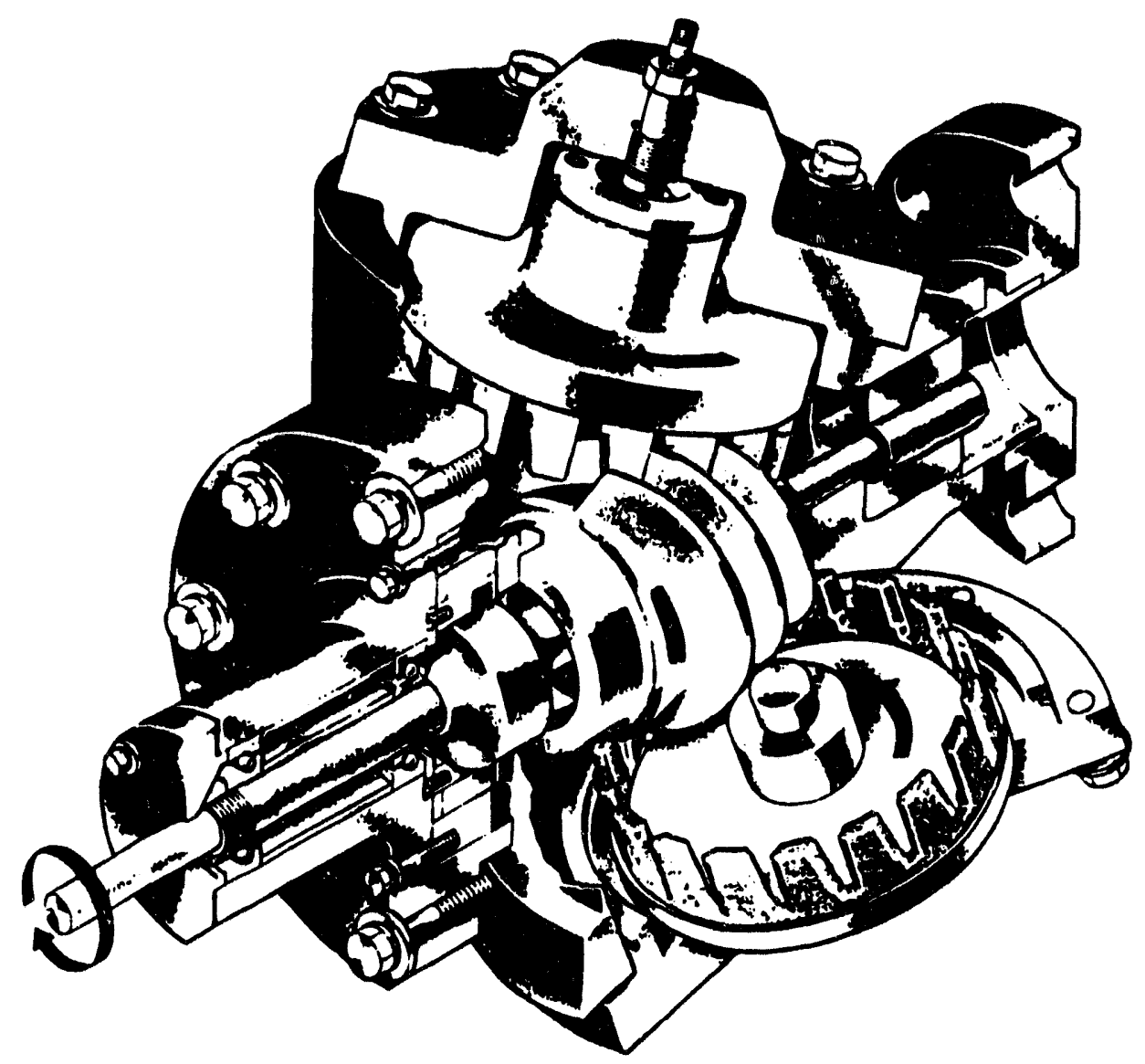

Single-screw pump 


\title{
Variable Capacity Centrifugal Pump
}

\author{
Harry Skrunch \\ David Tayior Research Center
}

A centrifugal pump has been developed and demonstrated that automatically varies the impeller geometry to maintain constant discharge pressure over a wide flow range. The impeller is made in two sections such that the raised vanes on one half of the impeller engage matching slots on the other half. Discharge pressure is applied to the back side of the impeller so that as the pressure increases, the force on the brck of the impeller also increases, thereby pushing the two halves closer together and diminishing the effective width of the impeller.

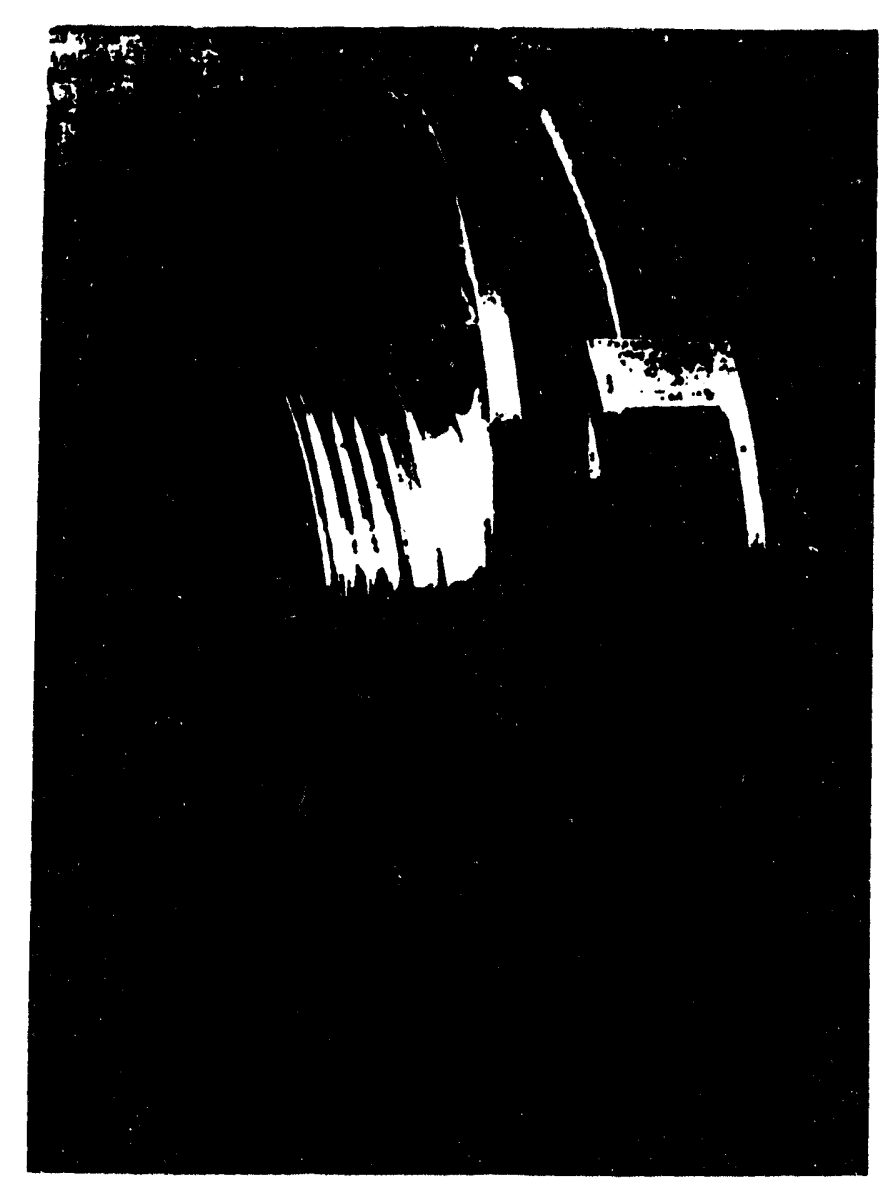

VCCP impeller 


\title{
Composite Materials for Ship Machinery Applications
}

\author{
George F. Wilhelmi
}

David Taylor Research Center

Modem composite materials have evolved from the fiberglass-reinforced plastic laminates introduced in the late 1940s. Composites offer the marine designer significant opportunities to improve the performance and service life of shipboard machinery and auxiliary equipment, while reducing weight and containing costs. The decline of the U.S. steel industry over the last decade, coupled with growing domestic consumption of advanced reinforced plastic materials and the existing composites technology base (pioneered by the aerospace community) provide additional incentive to develop new marine machinery applications. Now being studied are current and potential applications of composites in shipboard piping systems, valves, centrifugal pumps, heat exchangers, ventilation ducting, fans, propulsion shafting, hydraulic systems, and marine diesel engines. Future assessments include proposed composite material applications in tanks, reservoirs, and electrical enclosures. 


\title{
Design and Testing of a Balanced Air Regulator for Deep-Sea and Scuba Divers
}

\author{
LT Benjamin K. Miller, Jr., USN \\ Navy Diving Salvage Training Center
}

\begin{abstract}
A high-volume, low-pressure loss, balanced poppet valve was designed for use on demand type open-circuit underwater diving units. This supply valve acts as a diver's second-stage regulator providing air, on demand, to the diver with minimal breathing effort. The prototype was fabricated and tested in January 1984 by the Navy Experimental Diving Unit, Panama City, Florida. Test results showed that the unit met the U.S. Navy performance requirements for helmet-mounted second stage demand regulators. However, the valve/seat arrangement leaked excessively.

Modifications to the poppet valve and seat eliminated aerodynamic forces that were acting on the poppet valve's seating surface. Additionally, a compliant seat was used that eliminated gas leakage. Brief testing of the improved prototype on May 4, 1984 indicated that performance was equivalent or superior to performance of the best commercial second stage demand regulators available at the time of testing.

Current design modifications indicate that the regulator's performance can be further upgraded by using a newly designed cylindrical diaphragm. This will provide opening force to the poppet valve during inhalation, theoretically reducing diver breathing effort and the unit's size. Further modification of the balanced poppet valve and its seat would improve reliability and performance and reduce design complexity.
\end{abstract}




\title{
High-Definition, Video-Rate, Laser-Addressed Iiquid-Crystal Light-Valve Projection Display
}

\author{
John A. Trias
}

Naval Ocean Systems Center

This invention provides a high-definition, video-rate, laser-addressed liquid-crystal light-valve projection display on a distant screen with an acceptable resolution higher than 1000 TV lines. A laser beam is deflected by a laser raster scanner having an acousto-optic modulator, an acousto-optic beam deflector to tract the laser beam, an acousto-optic horizontal traveling lens deflector driven by a chirp, and a high-resolution, low-speed acousto-optic deflector for the vertical scan. This vertical scan scans a high-resolution beam on a liquid-crystal light valve that in turn spatially modulates the high-intensity light from an arc lamp source for projection onto a large screen.

U.S. Navy Case Number 71940 


\title{
Real-Time, High-Resolution, 3-D Large-Screen Display Using Laser-Activated Liquid-Crystal Light Valves
}

\author{
John A. Trias \\ Naval Ocean Systems Center
}

\begin{abstract}
A number of viewers wearing polarized glasses are presented real-time, high-resolution, threedimensional projected images on a distant screen at video image signal rates. Two laser raster scanners each activate one of two liquid-crystal light valves with information representative of lefi- or right-eye images. A high-intensity light source is polarized through a prism so that one component is directed to one liquid-crystal valve, and an orthogonal component reaches the other liquid-crystal light valve. Both components of the high-intensity light are modulated by the valves and are reflected back through se prism onto the distant screen. Laser diodes and solid-state vertical and horizontal deflection components in the laser raster scanners combined with the liquid-crystal light valves and a single bipolarizing prism result in a reliable, compact unit capable of providing long-term economical displays. Three-dimensional viewing in real time gives planners a more realistic appraisal of features such as terrain and obstacles so that responsive decisions may be reached and decisive action may be taken.
\end{abstract}

Patent Number 4,623,219 


\title{
Real-Time, Ultra-High-Resolution Image Projection Display Using Laser-Addressed Liquid-Crystal Light Valve
}

\author{
John A. Trias \\ Naval Ocean Systems Center
}

\begin{abstract}
A wide screen display enables a number of viewers the simultaneous viewing of rapidly updated data in real time at video rates. A beam of coherent radiation from a laser is modulated at video rates in an acousto-optic modulator. The modulated beam is fed to an $X$ scanner that imparts an acousto-optic displacement of the modulated beam in the $\mathrm{X}$ direction. A $\mathrm{Y}$ scanner is aligned to receive the $X$-scanned modulated beam and imparts an acousto-optic reciprocal displacement of the beam so that the video modulated beam is displaced in both the $X$ and $Y$ directions. A liquid-crystal light valve is disposed to receive the $\mathrm{X}$ - and $\mathrm{Y}$-displaced modulated beam so that it scans the surface of the light valve to stimulate the photosensor layers within. This causes the impression of a replica voltage pattern on a birefringent liquid crystal in the valve. A high-intensity lamp projects a high-intensity incoherent light beam onto the liquid-crystal light valve through a polarizing biprism. Since the birefringent liquid crystal has been modulated by the $\mathrm{X}$ - and $\mathrm{Y}$-scanned modulated coherent beam, a corresponding image is reflected from the birefringent liquid crystal and onto the screen. The acousto-optic modulation $X$ scan and $Y$ scan occur at much higher rates and with greater control than conventional arrangements so that the resolution of about $\mathbf{2 0 0 0}$ lines at a video rate is possible. The real-time display provides a number of viewers with a more realistic image so that responsive decisions and actions may be taken.
\end{abstract}

Patent Number 4,611,245 


\title{
Method and Apparatus for the Detection of Toxicants
}

\author{
Patrick J. Hannan, Arthur V. Stiffey, N. Lynn Jarvis, and Henry Wohltjen \\ Naval Oceanographic and Atmospheric Research Laboratory
}

This method and apparatus rapidly detects toxicants by the use of a first $\mathrm{CO}_{2}$ sensing cell and a second reference $\mathrm{CO}_{2}$ sensing cell. Each sensing cell includes a first chamber and a second chamber, separated by a $\mathrm{CO}_{2}$ permeable membrane and a pH sensor disposed in each of the second chambers. Distilled water is placed in the first chamber of each cell, and its dissolved $\mathrm{CO}_{2}$ becomes equilibrated with the water in the second chamber, from which it is separated by the $\mathrm{CO}_{2}$ permeable membrane. Next, exact amounts of a microorganism and sugar are added to small dishes in the first chambers along with control vegetation so one dish and vegetation to be tested to the other dish. Then the first chambers are completely filled with distilled water, and the dishes are agitated to facilitate a solution of microorganisms and sugar. The method further includes the steps of sensing the $\mathrm{pH}$ in the liquid contained in each of the second chambers, determining the difference between the outputs from the pH sensors, and generating an alarm signal if this difference equals or exceeds a predetermined threshold. In one embodiment, yeast is used as the microorganism.

Patent Number 4,513,280 


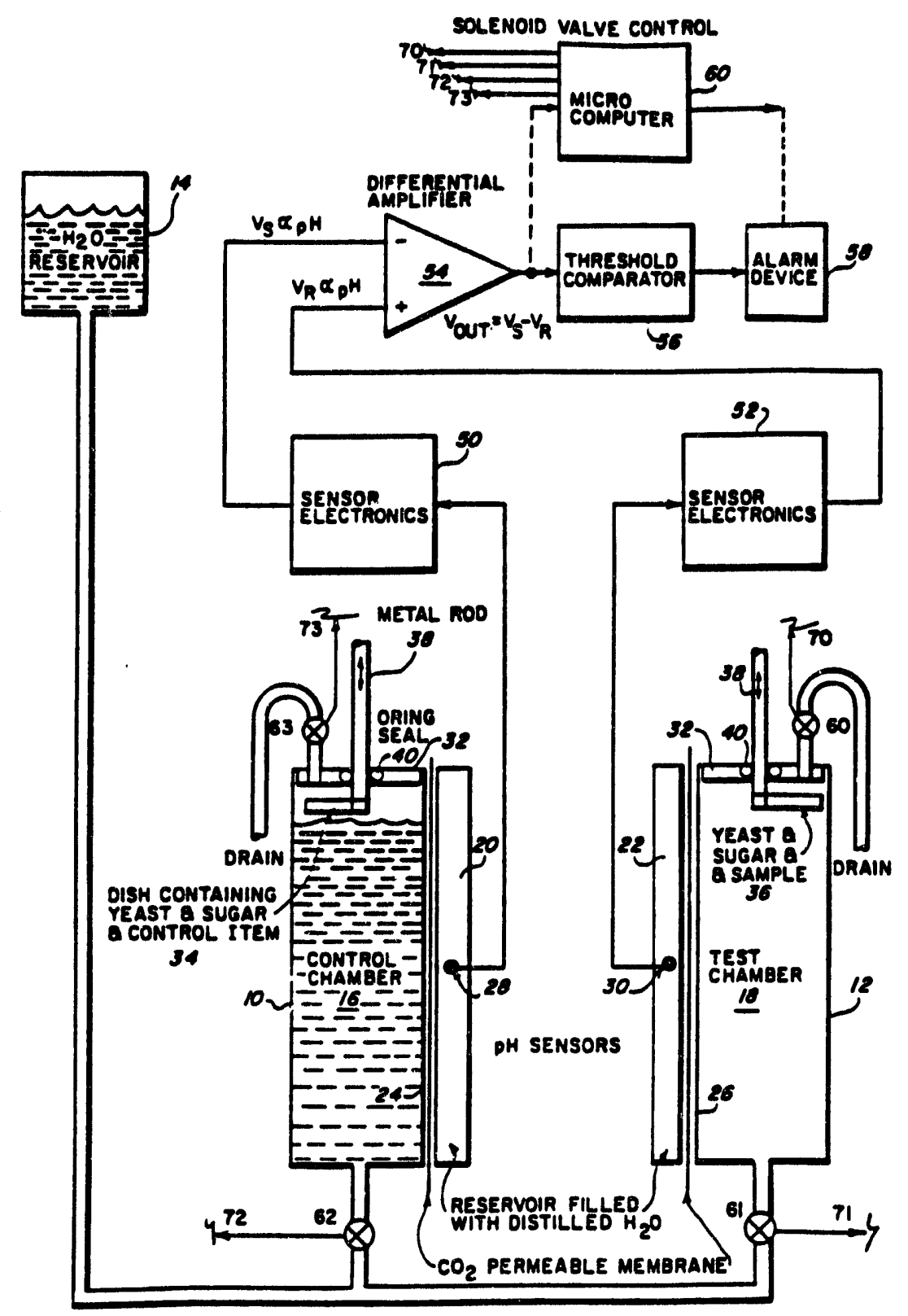

Toxicant detecting apparatus 


\title{
NRL Fluoropolymer Inventions, Materials, Uses, and Prospective Uses
}

\author{
James R. Griffith
}

Naval Research Laboratory

\begin{abstract}
During the recent Kansas City "TransFair," Dr. Jim Griffith discussed NRL fluoropolmyer development. He included in his talk the original rationale for the work, significant technical milestones that were accomplished with respect to materials properties, a cross section of the potential military and civilian applications in prospect as well as some of the problems involved, such as high unit cost. Chemical synthesis, which was at the heart of this effort, was discussed only minimally since four in the audience were trained in this discipline.

The fluoropolymer synthesis effort has resulted in fourteen U.S. patents of a basic materials nature of which eight are presently licensed and six are available for licensing. The most salient and promising features of the available patents were highlighted. Two spinoff-use patents in the areas of fiber-optic coatings and computer circuit board resins are now in process and are expected to be issued in the near future. These will also be available for licensing.
\end{abstract}




\title{
Holographic Optical Elements for Laser Diodes
}

\author{
Anne E. Clement \\ Naval Research Laboratory
}

At the Navy Domestic Technology TransFair this summer, Anne Clement gave a presentation on Holographic Optical Elements for Laser Diodes. The supporting research for this work was done about 3 years ago at NRL's Naval Center for Space Technology. This work was motivated by the payload advantages that may be gained by replacing bulky conventional optics with holographic optical elements on a satellite. The problems associated with doing holography with laser diodes include the absence of a readily available material sensitive to the infrared (IR) that has high resolution and high diffraction efficiency. In the production of consistently viable holograms with laser diode emission, the three most important steps are (1) quantifying the modal response of the laser diode as it warms, (2) turning off the cooler and other sources of environmental noise during exposure, and (3) continuously monitoring the diode's frequency stability. This process is the subject of a recently granted patent entitled, "Method for Making Holograms with Coherent Radiation from a Stablized Laser Diode Which Has Been Actively Cooled," by G. C. Gilbreath and A. E. Clement. 


\title{
Technological Opportunities in Biomolecular Engineering
}

\author{
Ronald R. Price \\ Naval Research Laboratory
}

\begin{abstract}
During the past 6 years, a group at NRL has accomplished a large range of patents and patent filings. The advancements include the range of self-assembling microstructures that the group has produced and uses and to which the technologies can be adapted. These range from composite materials to electromagnetic interference and radar absorbing material coatings, controlled release of antifoulant materials in Navy ship coatings, and controlled release of anticorrosive compounds, dyes, chemicals, and polymeric materials. Other materials developed by the group include a microencapsulated blood replacement that can function as a virus-free source of blood for Navy personnel. Research also includes freeze preservation technologies, biosensors, immunosensors for the detection of explosives, microlithography, molecular modeling with small computers, ultra-high-resolution lithography techniques, as well as fiber-optic based sensors with very sensitive detection capabilities.
\end{abstract}




\title{
Silver Oxide (AgO) Cathode
}

\author{
Steven Dallek \\ Naval Surface Warfare Center
}

Silver oxide/zinc $(\mathrm{AgO} / \mathrm{Zn})$ primary reserve batteries are in widespread use for various military applications. The AgO cathodes are electrochemically formed by anodization of sintered silver plates. In the reserve configuration, the $\mathrm{KOH}$ electrolyte is separated from the remainder of the cell to prevent self-discharge of the battery during storage. Nevertheless, the high decomposition (self-discharge) rate of many $\mathrm{AgO}$ cathode materials during reserve battery storage remains a problem of great concern. This thermal instability can result in severe degradation in battery discharge performance. For instance, $\mathrm{AgO}$ decomposes to form $\mathrm{Ag}_{2} \mathrm{O}$, which has a much higher ohmic resistance and causes a voltage regulation problem. The evolved $\mathrm{O}_{2}$ increases the internal cell pressure, which can cause an activation problem by preventing adequate injection of the $\mathrm{KOH}$ electrolyte into the cells. Furthermore, the reaction between the evolved $\mathrm{O}_{2}$ and the $\mathrm{Zn}$ anode, forming a film of $\mathrm{ZnO}$, results in increased polarization after activation. Capacity losses at both electrodes are also an obvious consequence of these processes. It is apparent that performance degradation problems with these batteries are related, ultimately, to the decomposition of the $\mathrm{AgO}$ cathode during storage of the battery in the weapon. As a result, such batteries need to be replaced periodically at great expense to the Navy.

We have developed a new AgO cathode material that has extremely high thermal stability. The standard charging procedure for sintered silver was modified by performing the charging at elevated temperatures $\left(70^{\circ}\right.$ to $\left.110^{\circ} \mathrm{C}\right)$. It was postulated that $\mathrm{AgO}$ material formed at high temperature should possess superior thermal stability; the formation of less stable modifications of the material would be impeded during the preparation procedure. Additionally, it is well known that thermally stable, chemically prepared $\mathrm{AgO}$ material, used in low-rate batteries, is synthesized at elevated temperature.

The new material was found to have extremely high thermal stability with a decomposition activation energy $E_{a}$ of $146 \mathrm{~kJ} / \mathrm{mol}$ determined by thermogravimetry. The $E_{a}$ values of other AgO materials range from 100 to $133 \mathrm{~kJ} / \mathrm{mol}$. The excellent thermal stability of the new material was confirmed by an accelerated aging study. Details of the preparation procedure and properties of the new AgO material can be found in the patent disclosure.

Patent Disclosure, Navy Case Number 71677 


\title{
Data Acquisition and Reduction Processor (DARP) for AN/UYK-43(V) Performance Monitor Interface (PMI)
}

\author{
James Deatherage \\ Naval Surface Warfare Center
}

The Data Acquisition and Reduction Processor (DARP) is a system of hardware components controlled by custom software and hardware resident in the DARP Control Computer (DCC). The DARP attaches to and captures data presented on the Performance Monitor Interface (PMI) of the AN/UYK -43 large scale militarized computer that replaces the AN/UYK-7 large scale militarized computer.

The requirement for an optional PMI on each Central Processor Unit (CPU) and each Input/Output Controller (IOC) was included in the original procurement requirements for the AN/UYK 13. The PMI provides passive access to numerous types of data that reflect the operation of the CPU and IOC. Special performance monitoring instructions are included in the Instruction Set Architecture (ISA) of the AN/UYK -43 to allow programs to pass specific data to the PMI.

The DARP provides the capability to capture AN/UYK-43 PMI presented data at the presentation speed of the AN/UYK-43. A time-tag is associated with each captured data word to allow correlation of data captured on multiple PMI data busses or to measure the time between the capture of multiple data items or eventsi. Captured data are stored in the resident DARP memory for later retrieval and into first-in-firs(:-out (FIFO) buffers for immediate retrieval and processing.

The AN/UYK-43 PMI and the DARP combine to open enormous possibilities for the evaluation of AN/UYK-43 hardware performance, overall system performance, and the support of software debug and analysis for AN/UYK -43 hosted combat system elements. Some general functions include (1) passive program trace, (2) monitoring of the active status register, (3) capture of program generated data by using the performance monitor instructions, and (4) evaluation of CPU and IOC loading in a particular system configuration. Although the PMI can operate with no AN/UYK-43 resident program support, detailed evaluations will be greatly enhanced by using carefully selected support mechanisms.

Methods utilized to evaluate system timing and performance in previous systems included (1) performing an input/output (1/O) process under system software control on an unused $1 / 0$ channel and performing timing measurements with an oscilloscope; or (2) accessing a 1- $\mu$ s accurate external clock through an I/O channel and extracting the timing information through another $1 / O$ channel to magnetic media for later analysis. The first method required little processing support from the system under test but, because of varying frequencies, large sample periods, and oscilloscope operator interaction, 
yielded fairly gross timing results. The second method yielded accurate results but placed a processing burden on the system under test, which could adversely impact the system as well as the timing results. Application of the DARP on an AN/UYK -43 should provide accurate timing data.

Although the DARP was designed for the AN/UYK-43 PMI, the DARP can be adapted to any interface that provides a signal to define that data are valid for sampling at a frequency not to exceed 6.67 MHz. DARP systems are currently in use with AN/UYK-44s and ROLM 1666Bs as well as AN/UYK-43s. 


\title{
Application of Global Positioning System Satellites to Determine Earth's Gravity and Platform Orientation
}

\author{
Alan G. Evans \\ Naval Surface Warfare Center
}

Navigation S\& sllite Tracking and Ranging (NAVSTAR) Global Positioning System (GPS) satellites are being placed in orbit to form a constellation that will enable a user to determine the position of a receiver's antenna anywhere over the Earth during all weather conditions. Eight satellites are available. These satellites have been used by the worldwide civilian community to very accurately determine relative position (the position of one antenna with respect to another) by using precise phase measurements of GPS receivers. Two extended applications of the GPS have commercial potential.

The first application combines GPS with accurate accelerometers to determine magnitudes of gravity values. Here, the accelerations from all forces on a moving platform are determined by dynamic GPS relative position, velocity, and acceleration techniques with respect to a fixed antenna location. The accelerations from all forces except gravity are obtained by the accelerometers. Corrections are made for Coriolis and Earth spin by using GPS-obtained values. The desired magnitude of the gravity vector is approximately equal to the magnitude of the vector difference between the GPS- and accelerometer-determined accelerations. For a very stable vehicle platform, such as a balloon, differencing the vertical component is sufficient. This gravity determination procedure can be used for balloon or aircraft vehicles flying over rugged or inaccessible terrain. Also, aircraft have the potential to perform rapid, less expensive gravity surveys, which may be used, for example, by the oil exploration industry.

The second application extends the GPS to determine a vehicle's orientation in addition to standard position. Here, an antenna is moved in a plane. This movement could be on a rotating plate or a windshield wiper arm-type movement. Since GPS antennas can be small, the mechanical motion can easily be accomplished. The mechanical antenna motion must be aligned to the vehicle and synchronized to the GPS measurements. Orientation, for example a ship's heading, can then be determined based on differences in antenna position. 


\title{
GPS-Aided Gravimetry at $30 \mathrm{~km}$ Altitude from a Balloon-Borne Platform
}

\author{
Andrew R. Lazarewicz \\ Air Force Geophysics Laboratory \\ Alan G. Evans \\ Naval Surface Warfare Center
}

\begin{abstract}
A balloon-borne experiment, flown at $30 \mathrm{~km}$ altitude over New Mexico, was used to test dynamic differential Global Positioning System (GPS) tracking in support of gravimetry at high altitudes. The experiment package contained a gravimeter (vibrating string accelerometer), a full complement of inertial instruments, a T1- 4100 GPS receiver, and a radar transponder. The flight was supported by two GPS receivers on the ground near the flight path. From the $8-h$ flight, about a 40-min period was selected for analysis. Differential GPS phase measurements were used to estimate changes in position over the sample time interval, or average velocity. In addition to average velocity, differential positions and numerical averages of acceleration were obtained in three components. Gravitational acceleration was estimated by correcting for accelerations caused by translation motion, ignoring all rotational effects.
\end{abstract}




\title{
CMSTOOL Version 1.2
}

\author{
Michael Peeler \\ Naval Surface Warfare Center
}

CMSTOOL was developed by the U.S. Navy to provide a range of sofiware quality measurements, including CMS-2 source code complexity; programming standards and style checking; and software maintenance indicators.

CMSTOOL is an automated software metrics tool for the analysis of CMS-2 computer programs. The tool provides a McCabe-based software complexity, measurement, subtasking level, percentages of commenting, direct code usage, and high-order language in the source code, program size, and a number of programming standards and style indicators. Seven quantitative metrics and twelve standard flags are generated by CMSTOOL. This tool supports software quality assurance efforts involved in CMS-2 based projects.

CMSTOOL analysis of CMS-2 embedded computer proyrams allows the system programmers and analysts to evaluate the software's characteristics in terms of modularity, understandability, complexity, portability, and maintainability. Data from the tool can also be useful in software test plan phases to ensure that testing priority/effort is focused on the high-complexity modules.

Present methods for extracting metrics from CMS-2 programs would be manual. Not only does CMSTOOL automate this process but it is also highly customizable for tailoring the standards and style indicators to specific, project defined software development guidelines.

The software package for CMSTOOL includes source program, executable code, VAX command files to support both interactive and batch processing, installation/user notes, and a program description document formatted for laser printing. 


\title{
Magnetostrictive Sensors and Actuators
}

\author{
H. T. Savage and Arthur E. Clark \\ Naval Surface Warfare Center
}

Most ferromagnetic materials show the phenomena of magnetostriction; a simple example is a ferromagnetic parallelepiped changing length when a magnetic field is applied along its axis. The change in length with magnetic field allows the parallelepiped to be used as an actuator. The change in length with field implies that an imposed change in length changes the magnetic moment of the material, which can be detected in several ways. Thus magnetostrictive materials can also be used as stress and strain sensors.

We discuss two materials: (1) the amorphous ferromagnetic materials (made by rapid quenching), which show great promise in sensor applications; and (2) alloys of $\mathrm{TbFe}_{2}$ and $\mathrm{DyFe}$ that have a W/m figure of merit equivalent to hydraulic actuators but with much higher frequency response and positioning accuracy. In material (1) we can "engineer" the physical characteristics of the amorphous materials to achieve properties more extreme in nature than in crystalline solids. This has led to the development of prototype magnetostrictive strain gages, torque sensors, pressure sensors, and accelerometers. Certain amorphous materials are being used in prototype magnetometers because of lower Barkhausen noise. Power transformers exploit the low (but still metallic) conductivity. The material has the highest figure of merit known for hydrophones (devices for underwater sound detection). Magnetostrictive strain gages show a figure of merit 1000 times higher than that of semiconductor strain gages. Amorphous wires have externally controlled magnetization characteristics (and other features) that make them useful in torque transducers. We discuss material preparation, prototype sensors, and the reasons for their high performance and possible problems that may arise in utilization.

With material (2) active vibration damping is the most prominent actuator application (the material is rather expensive to be used as a sensor). The material is capable of strains of $1.2 \times 10^{-3}$ with potential strains of $3 \times 10^{-3}$ with further material development. Stresses up to 7000 psi can be handled under steady state conditions. In magnetostrictive materials there are two contributions to the strain, one caused by the imposed stress and the other by the imposed magnetic field. Thus the strain is not necessarily zero if the stress is zero. By use of this and the nonlinear nature of the material, we show a new kind of active vibration control.
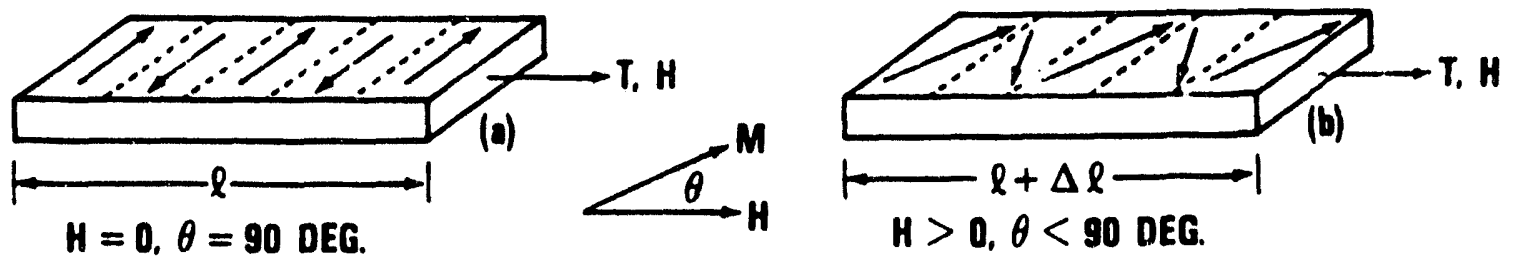

(a) The magnetization of a simple ferromagnetic parallelepiped. (b) As the the magnetic field increases the magnetix moment $M$ rotates and the parallelepiped elongates. A stress $T$ (or strain) will also rotate the moment. 


\title{
Method of Measuring Magnetic Effects Due to Eddy Currents
}

\author{
Paulo B. Tarr \\ Naval Surface Warfare Center
}

An eddy current magnetic field effects measurement apparatus employs a reference sensor located so that it measures an applied field and any environmental fields but does not measure eddy current effects. Then an estimate of the applied field at the locus of a plurality of measurement sensors is constructed and stored. Next, a conductive object or material to be measured is placed in the applied field near the measurement sensors away from the reference sensor, and measurements are made of the applied field, any environmental fields, and any fields caused by the effects of eddy currents induced into the conductive object or material. Finally, the stored estimates are used to compensate the applied field at the locus of the measurement sensors so that the eddy current magnetic field effects of the placement of the conductive object or material can be observed on a keyboard/display or printed by a printer or plotter.

Patent Number $4,648,041$ 


\title{
Nondestructive Inspection by Eddy Current Methods of Carbon Fiber Reinforced Composites and Metals
}

\author{
Susan N. Vernon \\ Naval Surface Warfare Center
}

The increased use of carbon fiber reinforced composites (CFRC) in the Navy and aerospace industries has generated a requirement for effective nondestructive technologies to inspect these materials. Because the fibers are conductive, CFRCs are amenable to inspection by eddy current methods. Furthermore, eddy current methods are more sensitive to different aspects of the material and its damage than are other nondestructive inspection (NDI) technologies. However, both the electrical and the damage characteristics prevent the effective application of eddy current systems and methods that have been developed for the NDI of metals. The four inventions each address particular problems presented by the unique characteristics of CFRC. They are also applicable to the NDI of metals.

The introduction includes a discussion of the basic elements of an eddy current system and the effect of the design of these elements on the sensitivity of the system to localized anomalies. This discussion is followed by a description of the characteristics of CFRC that affect the design of the elements of the eddy current system. The slightly different set of problems presented by filament wound CFRC is also discussed.

\section{INVENTIONS}

1. This method and device for measuring electrical resistivity (Susan N. Vernon and Paul M. Gammell) is based on the universal impedance curve associated with all ferrite pot core eddy current probes. The method uses the linear relationship between the tangent of the lift-off angle and a reference number. The tangent of the lift-off angle is the ratio of the change, caused by the test material, in the imaginary component of the impedance to the change in the real component. The reference number is the dimensionless ratio of the diameter of the ferrite pot core to the skin depth. This method does not require calibration standards and so is useful in the measurement of resistivities that fall in a range where such standards are not available. The device provides accurate phase detection over the necessary wide range of frequencies.

2. This method for measuring defect depth (Susan N. Vernon and Paul M. Gammell) is based on the universal impedance curve of the ferrite pot core probe. It provides estimates of the distance between the scanned surface and subsurface damage. This method requires no calibration standards and is particularly useful when the defects of interest do not have a "standard" or typical geometry.

3. This is a method for identifying the eddy current signat re of anomalous conditions in a material (particularly those occurring in CFRC) and a technique for accurately describing the size and 
shape of a fault (Reed Valleau and Thomas A. O. Gross). The identified conditions in CFRC are (a) thickness variations, (b) variations in localized conductivity such as may be associated with variations in fiber volume fraction, and (c) broken fiber damage. The resolution of the C-scan generated "image" of the damage is enhanced by double scanning with a C-core probe.

4. This device for the inspection of materials by eddy current methods (Susan N. Vernon and Stephen Lane) is particularly useful in the eddy current inspection of materials such as filament-wound CFRC that may not have sufficient electrical conductivity in off-circumferential directions to permit inspection by the use of axisymmetric eddy current probes. A circumferentially wound transmitter coil induces eddy current flow around the circumference of the test material. A discrete receiver, such as a U-shaped eddy current probe, a Hall probe, or a SQUID, detects localized changes in eddy current flow associated with anomalous conditions in the test material. 


\title{
Optimum Flow Noise Cancelling Hydrophone Module
}

\author{
John W. Fay \\ Naval Underwater Systems Center
}

This hydrophone module rejects turbulence-induced flow noise for towed hydrophone arrays. Two adjacent hydrophones in the array are spaced less than flow noise coherence distance apart and form a flow noise cancelling module. The inverted acoustic/flow noise signal from the lead hydrophone of the pair is split. One side passes to the final state of signal processing while the other side-filtered, amplified, and inverted-is added to the combined signal from the lag hydrophone, which has been filtered and amplified. The acoustic signal components cancel, leaving only the lead hydrophone flow noise plus the lag hydrophone flow noise, which has been shifted by a factor dependent on tow vessel speed and hydrophone spacing. This flow noise signal is combined in an adder-inverter with the delayed feedback from the output stage of this same adder-inverter. The lag hydrophone flow noise cancels leaving only the flow noise of the lead hydrophone, which is then combined with the acoustic signal plus flow noise output of the lead hydrophone. The flow noise components cancel, yielding only the signal of interest, free of flow noise and undistorted by rain or phase shifts.

Patent Number 4,388,711 


\section{Teletypewriter Loop Switching Matrix}

Robert R. Hartley and Joseph A. Konrad

Naval Underwater Systems Center

This matrix interconnects and switches teletypewriter or digital data signals when transmitted over any of the four universally accepted standard signal loops. The system incorporates a noval triple loop arrangement: an "IN" loop connected to a signal source, an "INTERNAL" loop to provide switching, and an "OUT" loop connected to the signal destination. Each "IN" loop or "OUT" loop together with half of its associated "INTERNAL" loop is implemented in a single printed circuit card. The system can incorporate any number of "IN" and "OUT" loops and the associated "INTERNAL" loops. 


\title{
Magnetic Field Transducer Systems
}

Theodore J. Mapes

\author{
Naval Underwater Systems Center
}

This invention provides a means for biasing and driving magnetic field transducers. The DC bias and the information-bearing AC modulation signal are derived from the same power supply. The drive circuitry, by changing characteristics external to the power supply, enables both the AC and DC current to flow from a common source through the transducer with the elimination of associated decoupling networks required for separate AC and DC supplies.

Patent Number $4,249,225$

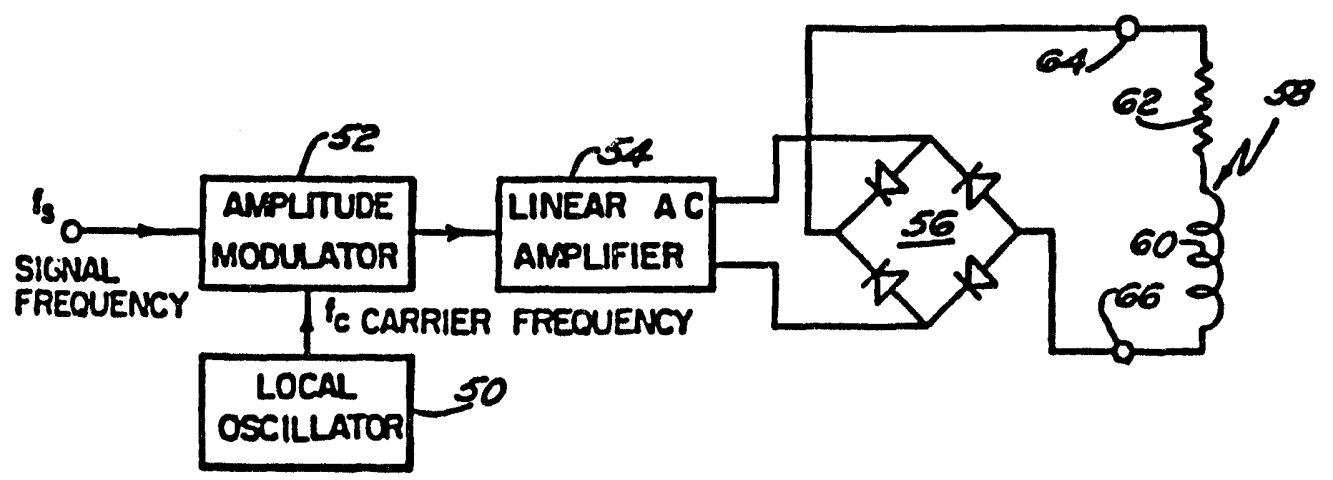




\title{
Electronic Noise-Reducing System
}

\author{
Harry B. Miller \\ Naval Underwater Systems Center
}

This method and apparatus reduces noise from a near-field noise source present together with signals from a far-field source. An adaptive shaping filter and a summer, in conjunction with a directional reference sensor and a primary sensor, have at least a common sensing element. The direction reference sensor, situated between the near-field noise source and the far-field signal source, rejects the broadband signal but accepts the broadband noise and feeds this noise into a reference channel of the adaptive filter. The primary sensor accepts both the far-field signal and near-field noise with equal sensitivity. The primary sensor feeds into the primary channel of the adaptive filter. The adaptive filter system subtracts the noise in the reference channel from the signal-plus-noise in the primary channel, thus producing an output having a greatly improved signal-to-noise ratio. 


\title{
Symmetric Waveguide Junction Combiner
}

\author{
Donald R. Bowling \\ Naval Weapons Center
}

This invention pertains to the fields of wave transmission lines, oscillators, and amplifiers. More particularly, the invention pertains to plural, parallel connected, transistor oscillators linked by a cavity. The symmetric waveguide junction exhibits several properties derived from its unique symmetry that make it a versatile modular component for building high-power or high-frequency microwave or millimeter $\mathbf{R F}$ sources.

This invention involves a waveguide junction power combiner of generally cubic symmetry with six rectangular waveguide ports extending from a spherical combining region in three pairs aligned with mutually orthogonal diameters of the region. Since the combiner is symmetrical, since the ports are well isolated, and since there are no planar surfaces and a minimal number of edges in the combining region, minimal reflections exist within and from the combining region; these reflections interfere with port isolation and create frequency-dependent effects. As a result, no circulator is required at any port of the combiner. Because frequency dependence effects are minimized, the combiner has a wide bandwidth and its inputs do not require tuning, which might affect connected devices and reduce bandwidth. 


\title{
Fire Extinguishing Material
}

\author{
Russell Reed \\ Naval Weapons Center
}

This invention provides fire extinguishing capability by providing solid gas generating compositions that generate large amounts of nitrogen gas when the compositions are burned. The compositions can be cast cured into small shapes and stored in a conveniently located container. It was found that compositions containing glycidyl azide polymer and a high nitrogen content solid additive or compound generate substantially large amounts of nitrogen gas when heated. The invention can provide a heating mechanism or allow heat of a fire to initiate. The compositions are specially useful in extinguishing fires that are confined in an area not easily accessible and in operations where the occurrence of fires is predictable. Examples are engine compartments in boats, oil refineries, and plane crashes.

Patent Number 4,601,344 


\title{
Improved Booster Explosive
}

\author{
Russell Reed \\ Naval Weapons Center
}

This presentation was actually a potpourri of inventions in the fields of explosives, pyrotechnics, and propellants.

1. Moldable Ethylene/Vinyl Acetate Copolymer; Patent Number 4,090,894.

This invention provides for a replacement for the standard Grade A wax, a petroleum derivative, which is more expensive and difficult to obtain. Ethylene vinyl acetate copolymer resins are used as desensitizers and binders of moldable explosive compositions. Press loading may be carried out at either room temperature (cold pressing) or at elevated temperature (hot pressing).

\section{In Situ Cured Booster Explosive; Patent Number 4,385,948.}

This invention relates to a method for preparing an in situ cured booster explosive by mixing explosive crystals with a prepolymer solution comprising a carboxyl (or hydroxyl) terminated hydrophobic polyester and epoxidized linseed oil with chromium octanoate as a catalyst. The explosive mixture is pressed into the desired shape and cured. The resulting in situ cured explosive has desirable safety and physical properties.

3. Impermeable Polymer Bomb Liner for Use with TNT Containing Explosives;

Patent Number 4,152,987.

This invention is for a polymeric bomb liner prepared froni a polyvinylidene chloride latex emulsion. This is a replacement for asphalt bomb liners. Although inexpensive and easy to apply, one major drawback is that asphalt is not impervious to trinitrotoluene (TNT). Another is that asphalt is exothermically reactive with hot TNT. Also, it hardens and cracks when subjected to thermal cycling. The polyvinylidene chloride overcomes these drawbacks. It can be readily applied to the inner surface of a casting from a latex emulsion and has the advantage of being inexpensive.

\section{Gelled Slurry Explosive; Patent Number 4,234,599.}

This invention provides an explosive slurry containing red water, a nitrocellulose containing propellant, oxidizer, passivated aluminum, and a thickening agent. These gelled slurry explosives can be made from waste products formed in the manufacturing of explosives and from excess gun and rocket propellants.

5. Polymer Modified TNT Containing Explosives; Patent Number 4,445,948.

This invention provides a melt cast explosive, TNT-based composition consisting of TNT, RDX, $\mathrm{HMX}$, aluminum, and an elastomeric linear polymer having polar groups dissolved or intimately 
dispersed throughout the composition. This provides an explosive composition having reduced hazard sensitivities such as cook-off, sympathetic detonation, and fragment initiation. These additives also substantially reduce cracking and exudation.

\section{In Situ Dye Smoke (Statutory Invention Registration); SIR H367.}

This SIR provides for a dye smoke that burns efficiently and without flame. Conventional smoke systems burn predominantly outside the smoke cannister, resulting in flaming. The flames can start fires if the smoke is being used as a marker. Oxidizers such as potassium chlorate and light metal fuels such as aluminum and magnesium generate large amounts of heat that pyrolyze the dye. This destruction of part of the dye reduces the efficiency of the dye smoke.

\section{Inhibited Gun Propellants; Patent Number 4,263,069.}

This invention relates to a method for improving the efficiency of and lowering the peak pressure produced by high force, high flame temperature gun propellants. A compound is defined for coating the propellant grain. This coating tends to lower the peak pressure and flatten out the pressure-time curve. When propellants are coated with this polymer, thinner wall chambers can be used, resulting in lighter weight guns. Another result is that the projectiles are fired with higher velocities.

\section{Multifunctional Polyalkylene Oxide Binders; Patent Number 4,799,980.}

This invention relates to energetic compositions containing an improved polyalkylene oxide binder. This improved binder is obtained by tailoring the cross-linking with a multifunctional polyol. When appropriate amounts of an energetic additive or oxidizer are added to the binder, particularly useful castable propellants and plastic-bonded explosives having high tensile strength and elongation and low volume dilation result. This also provides a propellant binder that is compatible with high levels of plasticizer. 


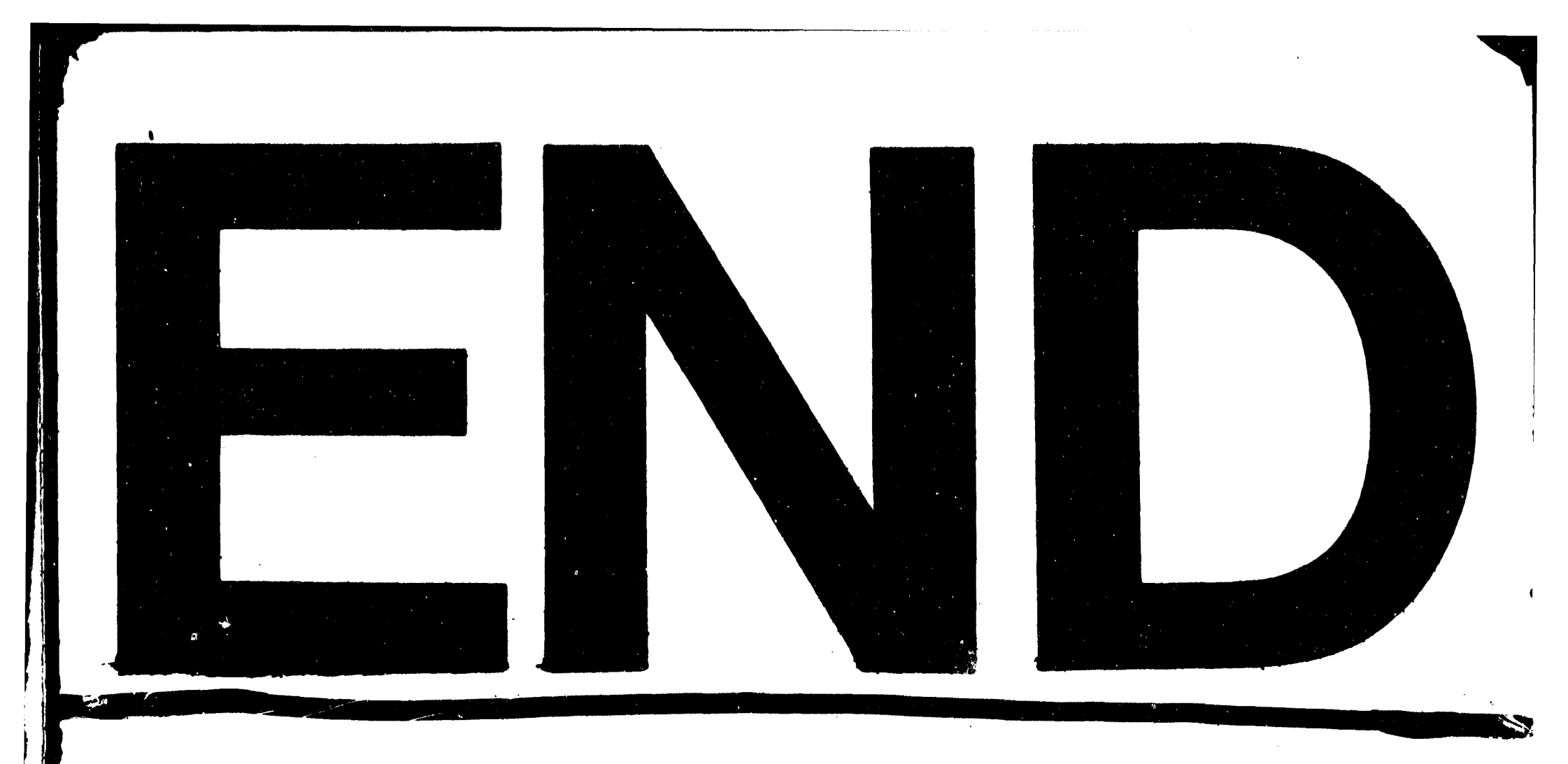



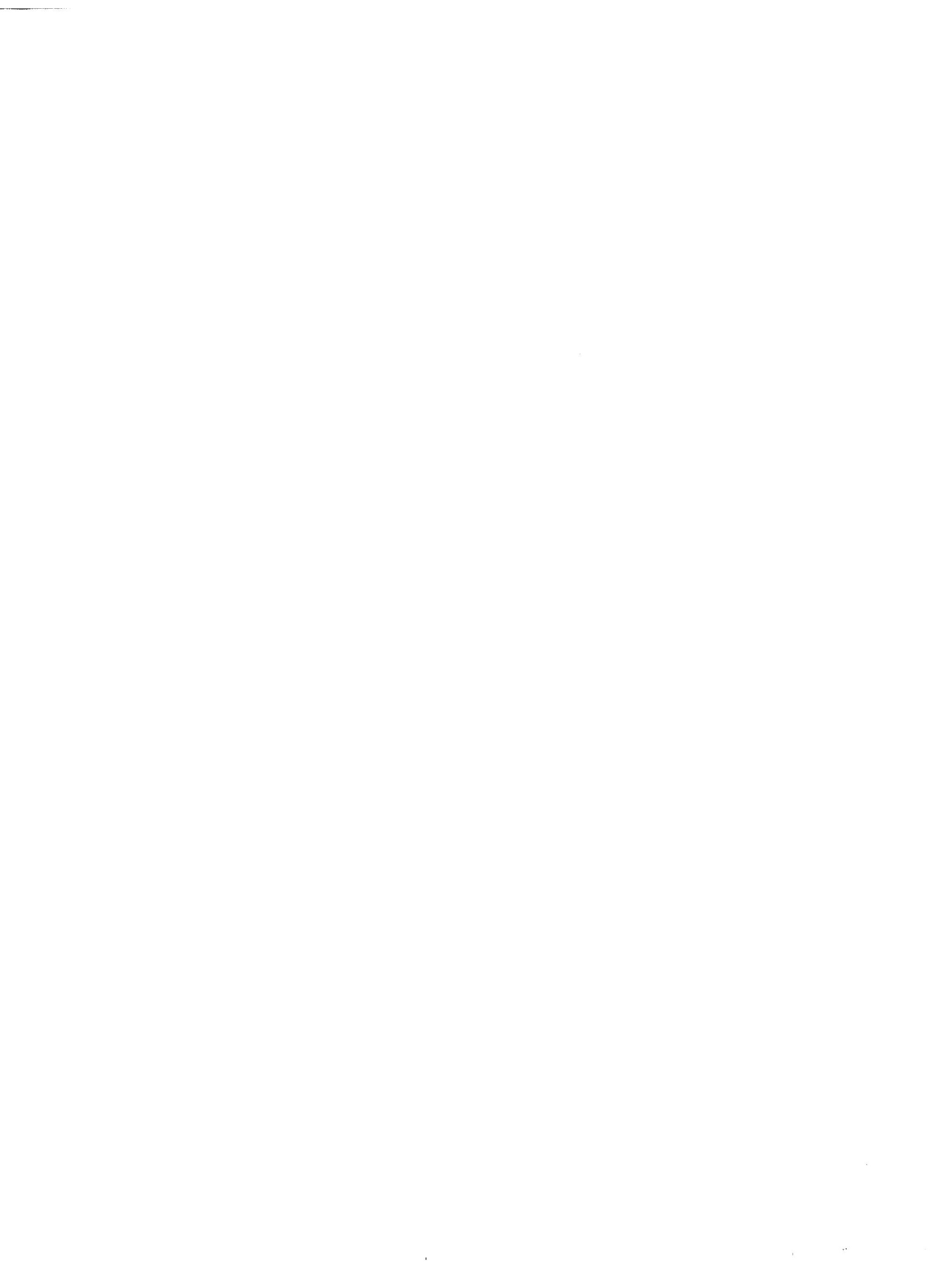